\title{
Effect of Hesperidin on Cardiovascular Disease Risk Factors: The Role of Intestinal Microbiota on Hesperidin Bioavailability
}

\author{
Anna Mas-Capdevila ${ }^{1,2,+}{ }^{+}$Joan Teichenne ${ }^{1,+}$, Cristina Domenech-Coca ${ }^{1,+}$, Antoni Caimari ${ }^{1,3}$, \\ Josep M Del Bas ${ }^{1}$, Xavier Escoté ${ }^{1,2, *(1)}$ and Anna Crescenti ${ }^{1, *}$ \\ 1 Eurecat, Technology Centre of Catalunya, Nutrition and Health Unit, 43204 Reus, Spain; \\ anna.mas@eurecat.org (A.M.-C.); joan.teichenne@eurecat.org (J.T.); cristina.domenech@eurecat.org (C.D.-C.); \\ antoni.caimari@eurecat.org (A.C.); josep.delbas@eurecat.org (J.M.D.B.) \\ 2 Department of Biochemistry and Biotechnology, Universitat Rovira i Virgili, Campus Sescelades, \\ 43007 Tarragona, Spain \\ 3 Eurecat, Technology Centre of Catalunya, Biotechnology Area and Technological Unit of Nutrition \\ and Health, 43204 Reus, Spain \\ * Correspondence: xavier.escote@eurecat.org (X.E.); anna.crescenti@eurecat.org (A.C.) \\ + These authors contributed equally to this work as first authors.
}

Received: 27 March 2020; Accepted: 18 May 2020; Published: 20 May 2020

\begin{abstract}
Recently, hesperidin, a flavonone mainly present in citrus fruits, has emerged as a new potential therapeutic agent able to modulate several cardiovascular diseases (CVDs) risk factors. Animal and in vitro studies demonstrate beneficial effects of hesperidin and its derived compounds on CVD risk factors. Thus, hesperidin has shown glucose-lowering and anti-inflammatory properties in diabetic models, dyslipidemia-, atherosclerosis-, and obesity-preventing effects in CVDs and obese models, and antihypertensive and antioxidant effects in hypertensive models. However, there is still controversy about whether hesperidin could contribute to ameliorate glucose homeostasis, lipid profile, adiposity, and blood pressure in humans, as evidenced by several clinical trials reporting no effects of treatments with this flavanone or with orange juice on these cardiovascular parameters. In this review, we focus on hesperidin's beneficial effects on CVD risk factors, paying special attention to the high interindividual variability in response to hesperidin-based acute and chronic interventions, which can be partly attributed to differences in gut microbiota. Based on the current evidence, we suggest that some of hesperidin's contradictory effects in human trials are partly due to the interindividual hesperidin variability in its bioavailability, which in turn is highly dependent on the $\alpha$-rhamnosidase activity and gut microbiota composition.
\end{abstract}

Keywords: cardiovascular diseases; hesperidin; hesperetin; gut microbiota; dysbiosis; bioavailability

\section{Introduction}

Cardiovascular diseases (CVDs) are the first cause of death in the world, causing about $31 \%$ of all deaths worldwide [1]. The development of CVDs are usually associated with the presence of several risk factors, some of them related with poor health habits [2-4]. Diet is a major external factor for CVDs development, and recommendations for the improvement of dietary and lifestyle routines and making them affordable and available for the general population are the primary approach to the prevention of the onset of this pathology $[5,6]$. In this sense, differences between dietary patterns, such as Mediterranean, Portfolio, Nordic, and vegetarian diet, are associated with different cardio-metabolic outcomes [7]. Nowadays, common therapies based on drugs are administered to patients who have already been diagnosed with any cardiovascular disorder [7]. Taking into account 
all the beneficial effects associated with the diet in CVDs development, the use of alternative treatments, such as natural-based products has gained importance as a preventive strategy for improving some CVD factors, such as hypertension, diabetes, cholesterol, and obesity [8]. In this sense, nowadays, research in food bioactive compounds is in the spotlight to develop new functional foods and nutraceuticals aimed at preventing and/or ameliorating CVD risk factors.

Polyphenols are a large group of bioactive plant compounds for which beneficial effects in the prevention and treatment of different pathologies, including CVDs, have been described [9]. The main classes of polyphenols are flavonoids, which include flavanols (e.g., tea), flavanones (e.g., citrus fruits), and flavonols (e.g., tea, apples, and onions), and nonflavonoids, including hydroxycinnamic acids (e.g., coffee) and anthocyanins (e.g., cherry) [10]. Of them all, flavanones, including hesperidin and naringin as the principal molecules, are considered the main subclass of polyphenols [11]. Orange and its fruit juice, which are considered rich sources of hesperidin and naringin, are the most common citrus fruit products consumed among the European population [12,13]. Hesperidin and, far behind, naringin, represent more than $90 \%$ of the flavonoids in sweet oranges $[14,15]$. The highest concentrations of hesperidin are found in the solid tissues of citrus fruits, although considerable amounts are also found in their juices [16]. In the form of supplements or nutritional complements, hesperidin is considered innocuous, with limited adverse effects, due to its nonaccumulative nature [17].

Hesperidin and its derived intestinal metabolites are shown in Figure 1. The number and specific position of hydroxyl groups in the flavanones aromatic rings, which produce important changes in their biochemical structure, are considered to be crucial for the reported beneficial effects of citrus polyphenols [18,19]. Some of these effects include antitumor, antioxidant, anti-inflammatory, hypocholesterolemic, and hypoglycemic effects, related to an improvement in different pathologies, such as cancer, neurodegenerative diseases or CVDs $[20,21]$. Regarding CVDs, the results of in vitro and in vivo studies have shown that hesperidin treatment produces beneficial effects on different risk factors, including the improvement of lipid and glucose metabolism, adiposity, and hypertension [22-26]. However, the results of human studies aiming to decipher possible beneficial effects of hesperidin on CVD risk factors are inconclusive, as there are studies that do not demonstrate beneficial effects of hesperidin on such factors.
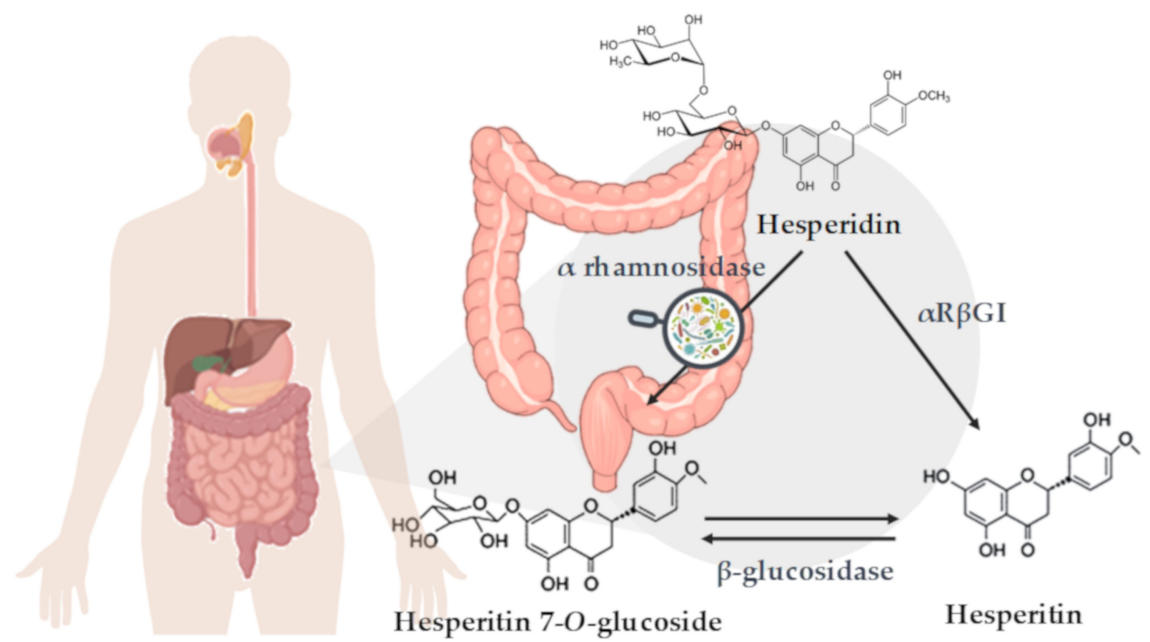

Figure 1. Schematic representation of hesperidin metabolization in the colon. Enzymatic deglycosylation of hesperidin to yield hesperetin: via hesperetin-7-O-glucoside by two specific monoglycosidases, $\alpha$-rhamnosidase and $\beta$-glucosidase, and via one-step deglycosylation through $\alpha$-rhamnosyl- $\beta$ glucosidase $(\alpha \mathrm{R} \beta \mathrm{Gl})$.

The molecular structure of hesperidin also affects its bioavailability and absorption levels [27]. Thus, the metabolism of citrus flavanones is determined by the sugar moieties and its removal degree by intestinal bacteria. Citrus flavanones are resistant to stomach and small intestine enzymes and 
thus reach the colon intact. There, intestinal microbiota activity breaks down the hesperidin molecule, releasing the aglycone form, named hesperetin [28,29] (Figure 1). Once inside the intestinal epithelium, hesperetin is released into the bloodstream in form of glucuronide and sulfatate conjugates [30]. In addition, an important part of the metabolized hesperetin is transformed by the microbiota present in the colon, generating some bioavailable and highly specific catabolites of hesperetin [30,31].

Bioavailability of hesperidin and its ability to produce beneficial effects can be modulated by different factors. Some of them are related with the food matrix and the physical form in which they are ingested (e.g., juice, soluble extract or capsules, among others), processing methods and storage techniques, as well as the structure of the compound and the host intrinsic characteristics, including intestinal microbiota composition [18]. All these factors affect the solubility of flavanones and their uptake by the gastrointestinal tract $[28,29]$.

Considering that the intestinal microbiota activity plays an important role in the bioavailability of hesperidin and, as a consequence, its beneficial effects on CVD risk factors, it is tempting to shed light on its intrinsic mechanisms [14,31,32]. Therefore, the present review aimed to describe the effects of hesperidin consumption on CVD factors and to highlight hesperidin interindividual variability in its bioavailability and effectiveness, a process in which the gut microbiota plays an important role. This reported variability would explain the discrepancies observed between animal studies and human studies on beneficial effects of hesperidin over CVD risk factors.

\section{Beneficial Effects of Hesperidin on Cardiovascular Disease Risk Factors}

\subsection{Effects of Hesperidin on Glucose Homeostasis}

Diabetes is one of the major risk factors for developing CVDs. The main complication of diabetes is CVDs, and it is estimated that $65 \%$ of diabetic patients die from CVD complications [33]. In this sense, several studies have shown beneficial effects of hesperidin in glucose metabolism at the preclinical level, both in animal and in vitro models.

At the in vitro level, neohesperidin (derived from hesperidin) treatment was shown to increase glucose consumption in the hepatocyte cell line HepG2, which was associated with increased phosphorylation levels of adenosine monophosphate (AMP)-activated protein kinase (AMPK) [34]. Xuguang et al. recently reported attenuated glucose content in culture medium and increased glucose uptake in lipopolysaccharide (LPS)-induced insulin-resistant HepG2 cells treated with hesperidin. These changes seemed to be associated with the regulation of the insulin receptor substrate 1 (IRS1)glucose transporter (GLUT)-2 pathway via toll-like receptor (TLR)-4 [23]. This positive effect over glucose uptake was corroborated in another recent study, showing that both hesperidin and hesperetin exert antidiabetic properties in L6 myotubes by inducing glucose uptake and reducing oxidative stress and advanced glycation end-products (AGEs) formation [22]. Related to AGE formation, Irshad and collaborators recently showed that a combination of trans-resveratrol and hesperetin is able to dampen the rise of methylglyoxal levels caused by high glucose concentrations by increasing the expression of Glyoxalase (Glo)-1 and decreasing the expression of hexokinase (HK)-2 in human aortal endothelial cells [35].

There is accumulating evidence demonstrating the glucose-lowering effects and the improvement in insulin resistance parameters exerted by hesperidin both in Type-1 diabetes (T1D) [36-41] and Type-2 diabetes (T2D) [42-46] rodent experimental models, thus demonstrating the antidiabetic properties of hesperidin. These effects were shown to be achieved by the modulation of key glucose regulation enzymes, such as an upregulation of glucokinase (involved in glycolysis) or a downregulation of the gluconeogenic enzyme glucose-6-phosphatase [36,40,42-44]. Other effects of hesperidin treatment in diabetic animals include a reduction in inflammatory parameters, such as tumor necrosis factor alpha $(\mathrm{TNF} \alpha)$, interleukin (IL)-6 or IL-1 $\beta$, and the reduction of oxidative stress associated with diabetes $[38,39,45]$. Akiyama and collaborators also reported a recovery of adiponectin levels mediated by hesperidin both in T1D and T2D models [36,44]. In addition to the effects observed in diabetic 
models, improvement of glucose metabolism and insulin resistance were also described by our group and others in other animal models of human diseases that are associated with alterations in glucose metabolism, such as metabolic syndrome (MetS) and obesity [47-51].

Despite all evidence at the preclinical level, the effects of hesperidin consumption on glucose metabolism in humans are not conclusive. In a recent randomized, double-blind, placebo-controlled clinical trial, Yari et al. reported that daily consumption of hesperidin capsules (500 mg) for 12 weeks significantly decreased fasting glucose levels, both compared with basal levels and with placebo group in patients with MetS [52]. Decreases in insulin levels and in the homeostatic model assessment for insulin resistance (HOMA-IR) index were also reported, although no significant differences vs. the placebo group were observed in these parameters [52]. Ribeiro et al. reported a decrease of $18 \%$ in insulin levels and a reduction of 33\% in HOMA-IR index after 12 weeks of daily consumption of $500 \mathrm{~mL}$ of orange juice (OJ) in obese individuals compared to control group [53]. Lima and collaborators also reported significant decreases in blood glucose and insulin fasting levels, as well as in HOMA-IR index after daily consumption of $300 \mathrm{~mL}$ of OJ during 60 days in a non-placebo-controlled clinical trial in healthy women [54].

However, to date, there are several clinical trials performed in different populations (healthy, obese, diabetic, or MetS) reporting no differences in glucose or insulin levels after chronic hesperidin or OJ consumption [55-60]. One study reported an increase in glucose levels in OJ-treated obese or overweight individuals, both in low and high hesperidin concentrations, which could be attributed to the daily addition to the diet of $500 \mathrm{~mL}$ dietary OJ during 12 weeks or to a decrease in insulin levels, which was also observed after the intervention [61].

\subsection{Effects of Hesperidin on Lipid Profile and Adiposity}

The dysregulation of lipid and lipoprotein metabolism contributes to the pathogenesis of multitude of human diseases, including CVDs [62]. Several therapeutic strategies exist to modulate lipid metabolism and prevent the development of metabolic diseases, but these strategies present some inherent limitations. For instance, statin drugs, which have been widely used to improve lipid profile and reduce atherosclerotic risk, present well recognized side-effects such as myalgia, arthralgia, and temporary gastrointestinal upset [63]. Those patients presenting dyslipidemia associated with MetS are unable to reach their lipid treatment goals by the administration of statin drugs [64]. Considering this, flavonoids including hesperidin have emerged as new therapeutic agents that could prevent alterations regarding lipid metabolism. In this sense, hesperidin has been shown to be especially effective in modulating dyslipidemia associated with MetS, which is considered a major risk for atherosclerosis, by exerting lipid-lowering properties in animal models and humans [47,54,58,65-69]. Jung et al. investigated the effects of hesperidin on lipid regulation in C57BL/KsJ- $d b / d b$ mice, a well-established model of obesity-induced T2D. The results of this study demonstrated that hesperidin $(0.2 \mathrm{~g}$ hesperidin $/ \mathrm{kg}$ diet) was effective in lowering the plasma free fatty acids (FFAs) and plasma and hepatic triglyceride levels after five weeks. Additionally, hesperidin reduced the hepatic fatty acid oxidation and carnitine palmitoyl transferase activity. Hesperidin effects on lipid regulation were attributable to a suppression of the hepatic fatty acid synthase, glucose-6-phosphate dehydrogenase, and phosphatidate phosphohydrolase activities and to an increase in the fecal triglycerides [43]. Furthermore, it was also demonstrated that hesperidin administration led to a decrease in plasma and hepatic cholesterol levels through a downregulation of the hepatic 3-hydroxy-3-methylglutaryl-coenzyme (HMG-CoA) reductase and acyl CoA: cholesterol acyltransferase (ACAT) activities [43]. Wu et al. demonstrated similar lipid-regulating effects with neohesperidin. Neohesperidin showed a potent hypolipidemic effect in HepG2 cells loaded with FFAs and reversed the pathological changes of lipid in the acute or chronic dyslipidemia mouse model. They suggested that neohesperidin regulates lipid metabolism in vivo and in vitro via fibroblast growth factor 21 (FGF21) and AMP-activated protein kinase/Sirtuin type1/Peroxisome proliferator-activated receptor gamma coactivator $1 \alpha$ signaling axis [51]. Hesperidin treatment has also been shown to reduce lipid 
accumulation in adipocytes derived from human mesenchymal stem cells by reducing lipogenesis and activating lipolysis [70]. Similar in vitro antiadipogenic effects have been observed in 3T3-L1 preadipocytes [71]. In addition, and related to lipid metabolism, Kim et al. have recently shown that hesperidin treatment increases Uncoupling protein 3 (UCP3) expression in differentiated C2C12 myocytes, thus boosting energy consumption from lipids [72].

The beneficial effect of hesperidin on atherosclerosis development was demonstrated in a study conducted by Sun et al. using LDL receptor deficient $\left(\mathrm{LDLr}^{-/-}\right)$mice. The authors observed that hesperidin ameliorated high fat diet (HFD)-induced hyperlipidemia and suppressed HFD-induced hepatic steatosis, atherosclerotic plaque area, and macrophage foam cell formation. According to these results, Sun et al. suggested that hesperidin reduced atherosclerosis in part via amelioration of lipid profiles, inhibition of macrophage foam cell formation, its antioxidative effect, and anti-inflammatory action [47].

Therefore, results from in vitro and animal studies demonstrate a beneficial effect of hesperidin treatment on lipid profile, but these findings are in contrast with some human intervention studies. Thus, while the administration of glucosyl hesperidin to hypertriglyceridemic subjects for 24 weeks resulted in a clear reduction in plasma triglycerides and apolipoprotein B levels [73], in other studies, the administration of hesperidin capsules did not affect plasma total cholesterol, LDL-cholesterol, or triglyceride levels in moderately hypercholesterolemic individuals [74].

Adipose tissue plays an important role in storing lipid in the form of triglycerides, as well as secreting a variety of adipokines and cytokines [75]. However, adipose tissue dysfunction is a determinant cause for the development of obesity, an independent risk factor for CVDs [75,76]. In this sense, there are several studies demonstrating that hesperidin exerts beneficial effects on lipid accumulation and adiposity $[71,72,77,78]$. In animal models of obesity or MetS, a body-weight-reducing effect has been widely reported in response to hesperidin treatment [47-51], as well as a reduction in adipose tissue weight $[25,48,50,51]$. In contrast, Mosqueda-Solis et al. reported no significant changes in body weight after a daily hesperidin administration $(100 \mathrm{mg} / \mathrm{kg}$ body weight) for eight weeks in Western-diet-fed rats, although hesperidin treatment resulted in a decreased size of adipocytes [78].

Similar to what has been observed in glucose and lipid metabolism, hesperidin or OJ treatment in obese or overweight individuals do not clearly reflect the effects observed in obesogenic animal models. Although Aptekmann and Cesar reported a significant reduction in body weight after daily consumption of OJ over 13 weeks in hypercholesterolemic subjects, no significant differences were observed between the intervention and control groups [68]. Rangel-Huerta and collaborators also observed a significant reduction in body weight after daily consumption of OJ over 12 weeks in obese or overweight subjects in a nonplacebo-controlled clinical trial [61]. By contrast, at least three studies reported no significant changes between control group and hesperidin or OJ groups in obese subjects $[53,67,79]$.

\subsection{Effects of Hesperidin on Blood Pressure and Endothelial Function}

High blood pressure is one of the most significant risk factors for developing CVDs in all age groups [80]. In fact, it is known that a reduction of 10 and $5 \mathrm{mmHg}$ in systolic blood pressure (SBP) and diastolic blood pressure (DBP), respectively, significantly decreases the relative risk of all major cardiovascular outcomes [81]. An extensive number of animal studies evaluating the cardioprotective role of hesperidin have shown its beneficial effects on high blood pressure [82-86]. The hypotensive effect after acute administration of hesperidin derivatives, hesperetin and glucosyl hesperidin (G-hesperidin), was demonstrated by Yamamoto et al. [24] in spontaneously hypertensive rats (SHR). In this study, a single oral dose of G-hesperidin (10 to $50 \mathrm{mg} / \mathrm{kg}$ ) induced a dose-dependent reduction in SBP in SHR, but had no effect in control Wistar Kyoto rats (WKY), discarding possible hypotensive effects under normotensive conditions. The antihypertensive effect of hesperidin was suggested to be mediated by the vascular nitric oxide (NO) synthase pathway. Similar effects were reported by Liu et al., observing an increase in NO production in hesperetin-treated human endothelial cells [87]. In this sense, Ikemura et al. [83] reported a preventive effect of hesperidin and G-hesperidin 
against age-related increase in blood pressure. This preventive effect of hesperidin seemed to be mediated by an important increase in NO production in the groups supplemented with hesperidin or G-hesperidin and by an improvement in the endothelial function [83]. The long-term effects of hesperidin and G-hesperidin on blood pressure were also evaluated when administered to SHR and to WKY. Chronic oral administration for 25 weeks of hesperidin and G-hesperidin resulted in a decrease in blood pressure after 15 weeks of administration in SHR, while no changes occurred in WKY [82]. Recently, it was also demonstrated that chronic administration of hesperidin for eight weeks resulted in a significant reduction in SBP in cafeteria-fed rats, a well-stablished animal model for diet-induced hypertension $[84,88]$. They observed that chronic administration of hesperidin in these animals presenting diet-induced hypertension also resulted in lower secretion of inflammation and oxidative stress-related metabolites. A reduction in inflammation and oxidative stress could be the underlying mechanisms involved in hesperidin effects on blood pressure in these animals [84].

These findings suggest that a potential mechanism whereby hesperidin and its derivatives, including G-hesperidin and hesperetin, exert their beneficial effects on hypertension through their demonstrated antioxidant effect $[20,83,89]$, enhancing NO bioavailability and protecting endothelial function from reactive oxygen species. Besides, several studies indicate that not only NO enhancement is involved in the antihypertensive effect exerted by hesperidin. The administration of hesperidin in SHR reduced blood pressure by reducing oxidative stress by the suppression of the renin-angiotensin system cascade [85]. In addition, hesperidin improved the reported oxidative stress observed under hypertensive conditions as a consequence of an overexpression of NADPH oxidase via suppression of this enzyme, which results in enhanced NO bioavailability [85,90,91].

Despite the beneficial effects observed in animal and in vitro studies, the results shown by human interventional studies are not consistent. Asgary et al. demonstrated that consumption of $500 \mathrm{~mL} /$ day of OJ decreased SBP and DBP in healthy subjects after four weeks [92]. Similar results were also reported by Morand et al. when evaluating the effect of daily consumption of $\mathrm{OJ}$ for four weeks in healthy volunteers [60]. In this study, it was stated that the beneficial effects on blood pressure maintenance induced by daily OJ consumption could be due to an improvement on endothelial function [60]. In another study, it was also demonstrated that six-week consumption of hesperidin improved blood pressure in T2D patients. The authors suggested that hesperidin exerts its beneficial effects via anti-inflammatory activity [93]. Furthermore, our group carried out a clinical study in which the beneficial effects of the consumption of $\mathrm{OJ}$ with natural hesperidin content and a hesperidin-enriched OJ on risk factors associated with CVDs, including its antihypertensive effects, in pre- and grade-1 hypertensive individuals were evaluated (submitted for its publication). However, the results of a crossover study that included individuals with MetS presenting prehypertension did not reveal changes in blood pressure after three-week supplementation with hesperidin [57]. Besides, a systematic review and meta-analysis of randomized controlled trials that evaluated the efficacy of hesperidin supplementation on blood pressure concluded that hesperidin intake is not associated with significant changes in blood pressure [94]. Similar results were reported by Plà et al. [95], concluding that hesperidin consumption effects on blood pressure were no conclusive.

There are many hypotheses that could explain why hesperidin lacks a significant effect on blood pressure in humans, including its metabolization and absorption. In this sense, Yamamoto et al. [26] reported that the hesperidin metabolite hesperetin-7-O-glucuronide, but not hesperetin-3-O-glucuronide, was the responsible agent for the demonstrated antihypertensive effect. Therefore, not all hesperidin metabolites present the same biological effects when administered. In addition, few studies are available to clarify the pharmacokinetics of hesperidin [96]. In consequence, it might be possible that hesperidin does not reach the sufficient circulating concentrations that are needed for the regulation of blood pressure.

In conclusion, the results from in vivo and in vitro studies point out that hesperidin represents a promising agent for the prevention and/or the treatment of CVDs. From these studies, it could be concluded that the potential mechanisms by which hesperidin exerts its beneficial effects include the regulation of gene expression and enzymatic activity of key proteins involved in pathways related to 
lipid and glucose metabolism, blood pressure control, and obesity development. Furthermore, it has been demonstrated the antioxidant and anti-inflammatory activities of hesperidin that may explain, at least in part, the observed beneficial effects on CVDs. However, despite all the evidences from in vitro and animal models, there is still controversy about whether hesperidin and their derivatives could contribute to ameliorating glucose homeostasis, lipid profile, adiposity, and blood pressure and thus reduce the cardiovascular risk, especially in humans (Figure 2). A possible explanation for the lack of conclusive results from human studies might be related to the presence of several important factors, including interindividual differences and external factors that impact the effectiveness of hesperidin in humans, including interindividual differences and external factors, with the variability of hesperidin bioavailability due to differences in intestinal microbiota composition and activity among individuals being a major factor. Although a low bioavailability of hesperidin has been described in animal studies $[97,98]$, the variability in studies with experimental animals is much lower than that observed in clinical studies due to inbreeding, leading to a phenotypic uniformity between the animals. Furthermore, external factors such as diet, physical activity, or seasonality are much more controlled than in human studies, leading to lower variability in intestinal microbiota composition and activity. Further well-designed clinical trials to specifically examine the effects of hesperidin on CVD risk factors, considering the variability that exists in the response to treatment with hesperidin in humans, are necessary. In this sense, intestinal microbiota may play a role in this interindividual variability, as it has been shown to have a direct effect on the absorption and bioavailability of polyphenols, such as hesperidin.

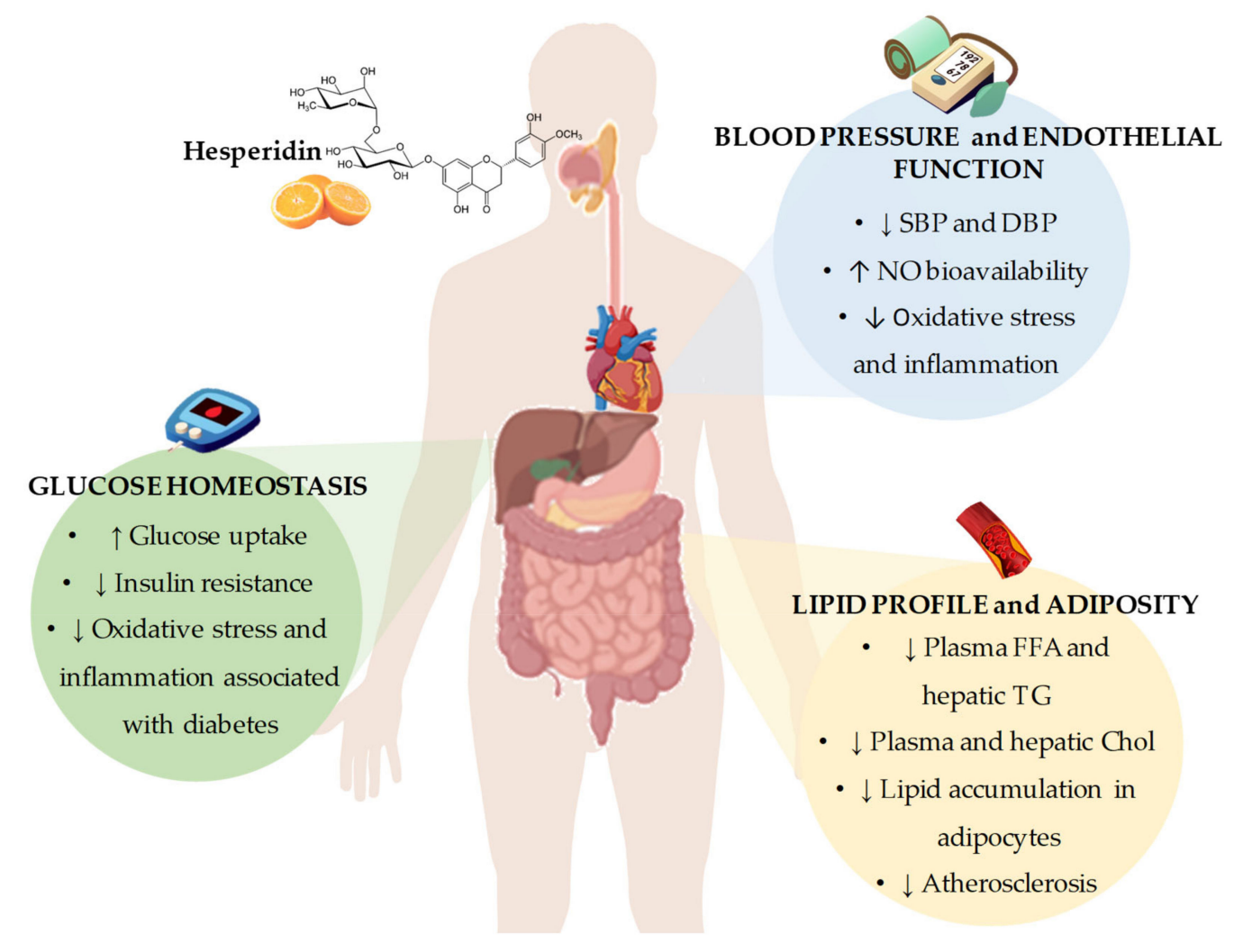

Figure 2. Summary of the most representative effects of hesperidin consumption and its derivatives on cardiovascular risk factors, including glucose homeostasis, blood pressure and endothelial function, and lipid profile and adiposity. SBP: systolic blood pressure; DBP: diastolic blood pressure; NO: nitric oxide; FFA: free fatty acids; TG: triglycerides; Chol: cholesterol. 


\section{Hesperidin and Intestinal Microbiota Interaction}

The gastrointestinal tract is colonized by more than $10^{11}$ cells per $\mathrm{mL}$ of content, with the five main microbiota phyla being Firmicutes, Bacteroidetes, Proteobacteria, Actinobacteria, and Verrucomicrobia [99]. The intestinal microbiota is a complex ecosystem that varies between individuals and environmental conditions [100]. The gut microbiota plays an essential role in physical health status, and it is responsible for protecting the intestinal gut barrier mucosa against several pathogenic microorganisms, modulating the immune system, and producing some molecules that are beneficial for their hosts, such as vitamins or short chain fatty acids (SCFAs) [101].

\subsection{The Gut Microbiota Assists in The Assimilation of Polyphenols}

The gut microbiota present in the colon promotes absorption of some nutrients from the diet, including polyphenols, forming more bioactive and absorbable molecules than the original compounds directly consumed in food [102]. Both polyphenols and microbiota-derived metabolites may act on metabolic pathways and confer health benefits [103]. In addition, polyphenol metabolites derived from microbiota activity may contribute to the host with numerous health benefits [104], which are mainly summarized by two of their characteristics: (1) polyphenol antioxidant properties and (2) polyphenol antimicrobial capacity over various microorganisms, including some pathogenic bacterial species.

\subsection{Hesperidin: A Flavonol That May Promote a Healthier Profile of the Microbiota}

Some clinical studies have demonstrated the role of polyphenols, supplemented in several food products, in maintaining the intestinal health and preserving microbial homeostasis by promoting the growth of beneficial bacteria and inhibiting the progression of pathogenic bacteria [105]. Indeed, polyphenols and hesperidin can modulate gut microbial composition or functionality, which affects the release of microbial-derived metabolites [106]. Flavonols are active inhibitors against some Gram-negative bacteria, such as Prevotella spp., Porphyromonas gingivalis, Fusobacterium nucleatum, E. coli, Pseudomonas aeruginosa, and Clostridium spp. $[107,108]$ (Figure 3). In addition, hesperidin and other flavonols also inhibit the growth of some Gram-positive bacteria, such as Staphylococcus aureus and Lactobacillus acidophilus $[107,108]$. Besides their inhibitory capacity, phenolic compounds may modify gut microbiota by selectively promoting the growth of beneficial bacteria of the genera Lactobacillus or Bifidobacterium [109,110].

There is growing evidence suggesting that polyphenols may induce changes in the microbiota towards a more favorable composition and activity, including the production of SCFAs in the large intestine. These polyphenols derived metabolites have many known biological effects: (1) they are used as energy source for enterocytes [111]; (2) they improve gut barrier function [112]; and (3) they inhibit inflammation processes [112,113]. However, gut microbiota alteration, also known as dysbiosis, might also reduce the synthesis of SCFAs [106]. Concretely, butyric acid is used as an energy source for colonocytes and improves gut barrier integrity by promoting mucus secretion and increasing tight junction protein expression (essentially zonulin and occludin), which is translated to a reduced bacterial transport across the epithelium [114]. Propionic acid attenuates the secretion of several inflammatory cytokines and chemokines [115] and regulates key liver processes, such as gluconeogenesis [116]. Acetic acid may induce liver lipogenesis [116]. Firmicutes are the main butyrate producing bacteria in the human gut, especially Clostridium leptum, Faecalibacterium prausnitzii, Roseburia spp., and Eubacterium rectale. In addition, propionate and acetate are mostly produced by the Bacteroidetes phylum [117]. The negative effects of dysbiosis are partially compensated by hesperidin, as has been demonstrated in different animal studies, playing a dual role over both beneficial and harmful microbes [112]. Hesperidin selectively promotes the growth of some beneficial Lactobacillus species [113] and inhibits the growth of some harmful species, such as Helicobacter ganmani or Helicobacter hepaticus [112]. In contrast, hesperidin treatments also inhibit the growth of beneficial species as Bifidobacterium pseudolongum or Mucispirillum schaedleri [112] and promote the presence of harmful 
species as Staphylococcus sciuri and Desulfovibrio [112]. Additionally, hesperidin supplementation reduces gut inflammation by decreasing plasma levels of key proinflammatory cytokines (IL-1 $\beta$, TNF- $\alpha$, and IL-6) [112], reducing the colon mRNA expression of a key proinflammatory mediator, the inducible nitric oxide synthase (iNOS) [112], and increasing the small intestine IgA content [113]. Besides, hesperidin maintains intestinal gut barrier integrity, reducing key markers of intestinal integrity such as colon length, and plasma levels of intestinal fatty acid binding protein (iFABP) and lipid binding protein (LBP) [112]. In addition, hesperidin also promotes the expression of the three main tight junction components: claudin 2, occludin, and zonula occludens-1 [112]. These results show the immunomodulatory actions of hesperidin on the gut and reinforce its role as a prebiotic; however, deeper studies of hesperidin effects on gut microbiota are necessary to completely understand these potential discrepancies.

\subsection{The Gut Microbiota Dysbiosis is Associated with Increased CVD}

Gut microbiota dysbiosis and microbial infections are associated with several metabolic chronic disorders, including obesity, T2D, MetS, and CVDs. Fortunately, and as pointed in previous sections, polyphenols can promote a healthier state by improving the lipid and glucose metabolism [118], but at the same time, metabolic diseases may modify the gut microbiota composition [119]. In fact, the gut microbiota may regulate the development of metabolic disorders, not only by modulating nutrient absorption, but also by regulating intestinal barrier health, the low-chronic inflammation state and fat storage, processes that are tightly associated with the development of CVD risk factors [120,121]. In this line, numerous studies have demonstrated that obese subjects present a reduction in gut microbiota diversity compared to lean subjects [122] and, at the same time, subjects with low bacterial richness showed an increased dyslipidemia, adiposity, insulin resistance, and inflammatory state [120]. These evidences were confirmed when obese subjects were transplanted with the gut microbiota of lean donors [123]. After the transplantation, the gut microbiota of obese subjects presented an increase in bacterial diversity, with an associated increase in butyrate-producing bacteria and subsequent increase in insulin sensitivity [123]. Similar results were observed in animal models of transfected gut microbiota [120]. In this sense, germ-free mice transplanted with the microbiota of obese mice $(o b / o b)$ donors, which harvest more energy than their lean counterparts, presented an increase in plasma leptin levels and elevated fasting glucose, which was translated with a systemic insulin resistance [124]. These results can be partly explained by the increased hepatic lipogenesis, which would be a consequence of the gut microbiota metabolization of indigestible polysaccharides into monosaccharides that posteriorly could be absorbed in the colon [120,125].

Moreover, obese subjects also exhibit an increase in Firmicutes, which leads to an increased Firmicutes/Bacteroidetes ratio [122]. A higher Firmicutes/Bacteroidetes ratio is associated with higher energy absorption from food, increased low-grade inflammation, and the development of obesity and insulin resistance [122,126]. In fact, gut microbiota dysbiosis is considered as a key contributor to the growing prevalence of obesity and associated cardiometabolic disorders, such as MetS or T2D [104]. Thus, Akkermansia muciniphila, a bacterial species increased by dietary polyphenols, was correlated with increased levels of some hormones such as glucagon-like peptide (GLP)1 and GLP2, which in turn promote insulin sensitivity [116]. In addition, A. muciniphila presence is reduced in obesity, and its levels are inversely related to adipose tissue mass and plasma glucose levels [125]. 


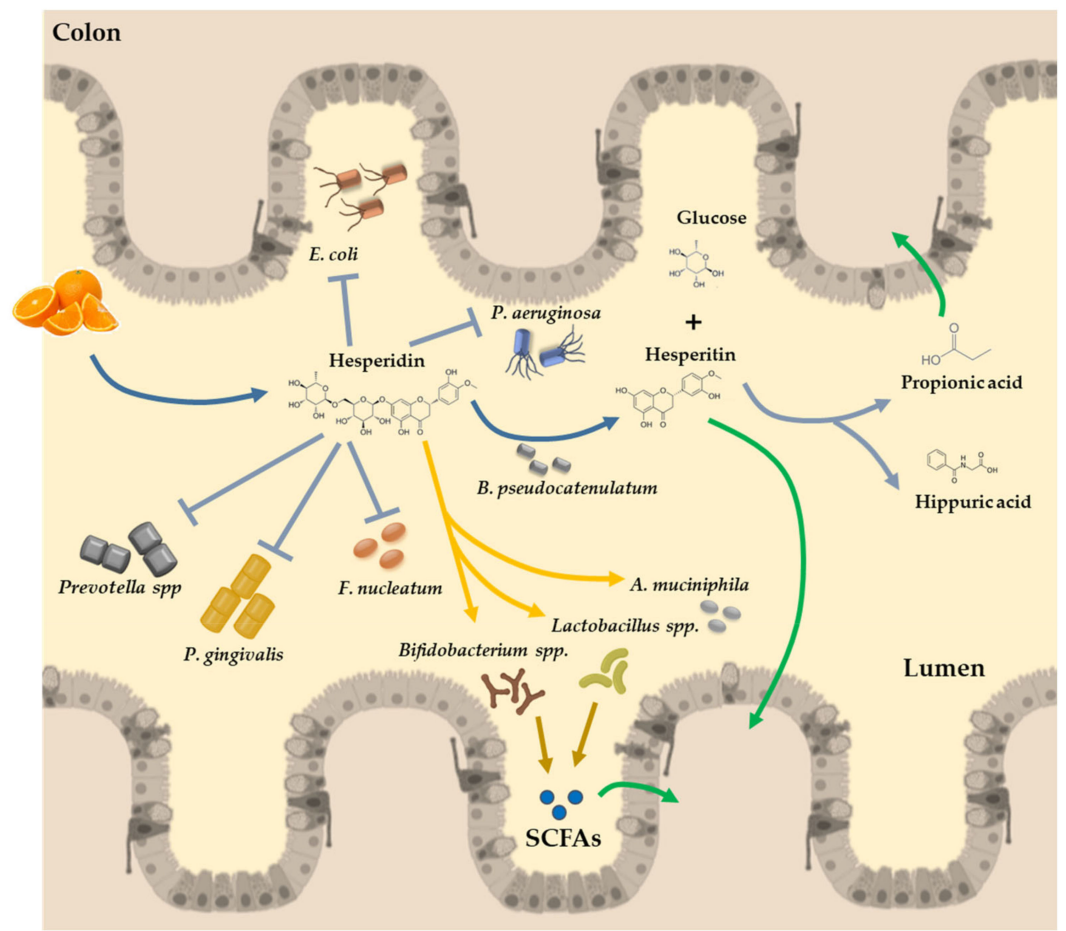

Figure 3. Illustrative diagram of hesperidin absorption in the colon. The flavones present in oranges reach the colon almost unchanged in their structure. In the lumen of the colon, hesperidin is converted to its active form by the $\alpha$-rhamnosidase activity of the microbiota (Bifidobacterium pseudocatenulatum), releasing the rutinose moiety and hesperetin for further absorption by the colonocytes. In the colon, hesperidin promotes the growth of some beneficial bacteria species, with a key role in the SCFA production (Bifidobacterium spp., Lactobacillus spp., or Akkermansia muciniphila). SCFAs are absorbed with healthy effects in the permeability of the gut barrier and in distal organs and tissues. Moreover, hesperidin has other beneficial effects by inhibiting the proliferation of detrimental bacteria, such as Escherichia coli, Pseudomonas aeruginosa, Prevotella spp., Porphyromonas gingivalis, and Fusobacterium nucleatum, among others. SCFAs: short chain fatty acids.

In gut dysbiosis, LPS, a key component of the Gram-negative bacterial membrane, promotes macrophage infiltration in adipose tissue, which in turn induces inflammation through the TLR4. LPS activates the inflammatory response by binding and activating TLR4, which triggers a signaling cascade that promotes the translocation of nuclear factor kappa-light-chain-enhancer of activated B cells (NF-kB) into the nucleus, where it stimulates the transcription of several inflammatory cytokines. However, some diet polyphenols, such as hesperidin, can increase the abundance of Faecalibacterium prausnitzii, which inhibits NF-kB activation and consequently attenuates the inflammatory response [9]. Increased LPS plasma levels disrupts the gut barrier permeability, probably due to reduced expression of key proteins that compose the tight junction, zonulin and occludin. These proteins contribute to form an impermeable intestinal epithelial barrier that prevents bacterial translocation and prevents harmful products derived from bacterial action reaching the bloodstream [115]. The intestinal mucosa may be considered as a complete immunological organ which contains immune cells, immunoglobulins (essentially IgA), and the microbiota [127].

In conclusion, studies investigating the effect of flavanones derived from oranges on the intestinal or fecal microbiota were mainly focused on their ability to inhibit the growth of pathogens, to increase beneficial species such as Bifidobacterium spp. and Lactobacillus spp., and to stimulate the production of SCFAs (Figure 3). In fact, the relation between polyphenols and the gut microbiota is bidirectional. In the case of hesperidin, this flavanone can promote specific favorable bacterial species [128] and at the same time, hesperidin can be metabolized by specific microbiota bacteria $[129,130]$. 


\subsection{Hesperidin Conversion to Hesperetin by the Microbiota Action}

After food intake, hesperidin is poorly absorbed in the small bowel [10,29]. In fact, hesperidin absorption is highly dependent on the conversion to its active form, hesperetin, by the microbiota, and this phenomenon occurs mainly in the large intestine, where gut microbiota releases the rutinose moiety for further absorption by the colonocytes [129] (Figure 3). This conversion of hesperidin to hesperetin can be promoted by some specific microorganisms such as Bifidobacterium pseudocatenulatum, which can hydrolyze specific rutinose-conjugated polyphenols, which in turn release the aglycone form [130]. Therefore, B. pseudocatenulatum may potentially contribute to improving the bioavailability of hesperidin, which is particularly relevant because Bifidobacteria and polyphenols are significant components of the human diet, becoming a potential probiotic to improve the hesperidin absorption [29].

Deeper investigations are necessary to decipher the effects of hesperidin on the gut-associated lymphoid tissue, where hesperidin reaches first and, moreover, where it can interact with the gut microbiota, contributing to the crosstalk between gut bacteria and intestinal immune tissue. As stated above, polyphenols are extensively metabolized in the colon by the gut microbiota into several lower molecular weight and more absorbable parts, which might be responsible for the beneficial health effects [131], as occurs in the case of hesperidin. After absorption, these catabolites reach the bloodstream and are distributed systemically to the whole body, thereby altering the metabolome and influencing host health [84]. Summing up, thanks to the gut microbiota activity, flavanones, specifically hesperidin, are catabolized in the colon, increasing their bioavailability [132] and thus their potential beneficial effects on health. Among the species with the capability to produce these transformations are Bifidobacteria and Lactobacillus species, which are used as probiotics in many commercial food products and dietary supplements [114,133].

\section{Hesperidin Bioavailability}

For hesperidin to exert its beneficial effects, except for its effects on the colon, its metabolites and catabolites arising from the intestinal microbiota must be bioavailable and absorbed to be distributed through the bloodstream. In this sense, several bioavailability studies in humans showed a scarce and variable hesperidin absorption among individuals. Thus, in a clinical study with pure hesperidin intake of $89.1 \mathrm{mg}$, a cumulative urinary recovery in urine of $2 \%$ was observed [134]. Most studies on hesperidin bioavailability have been performed with OJ. In these studies, the consumption of between $250 \mathrm{~mL}$ and $1250 \mathrm{~mL}$ OJ resulted in a total flavonoids metabolites recovery (including hesperidin and naringin metabolites) in urine between $2.9 \%$ and $24 \%$ [30,31,135-138] (Table 1).

Hesperidin bioavailability studies show that there is a high interindividual variability in its bioavailability [30,31,134,135,138,139]. In fact, the stratification of individuals as high, intermediate, or low hesperidin metabolite excretors has been proposed, as assessed by urinary excretion of hesperidin metabolites [30,31,134,135,138,139].

The clinical studies discussed above described hesperidin bioavailability by quantifying hesperidin metabolites excreted in urine in the form of glucuronide or sulphated conjugates relative to the amount of hesperidin consumed. Nevertheless, a substantial portion of hesperetin is further metabolized by the microbiota present in the colon to bioavailable catabolites, including highly specific catabolites of hesperetin such as 3-(3'-hydroxy-4'-methoxyphenyl) propionic acid (HMPPA) as well as less specific catabolites like hippuric acid, 4-hydroxyhippuric acid and 3-(3'-hydroxyphenyl) hydracrylic acid (HPHPA), which may also result from other phenolic sources [31]. Interestingly, it has been described that bioavailability of hesperidin increases considerably if the catabolites generated by the intestinal microbiota, such as HMPPA, are considered. In fact, different bioavailability studies in humans that included the measure of these catabolites observed a wide spectrum of urinary excretion levels of hesperidin metabolites and catabolites relative to the consumed flavonoid of 45.9\% [31], 64.2\% [30], and $100 \%$ [137] (Table 1). As a result, quantifying metabolites and catabolites generated by the microbiota provides a new perspective in the bioavailability of hesperidin. 
Table 1. Hesperidin bioavailability expressed as percent urinary excretion in human intervention studies.

\begin{tabular}{|c|c|c|c|c|c|}
\hline Administration Form & $\begin{array}{c}\text { Hesperidin Dose } \\
(\mu \mathrm{mol})\end{array}$ & Population & Measured Metabolites & $\begin{array}{c}\text { Relative Urinary Excretion } \\
(\%)\end{array}$ & Reference \\
\hline $\begin{array}{l}\text { Conventional Hesperidin } \\
\text { Micronized Hesperidin } \\
\text { Encapsulated Hesperidin }\end{array}$ & $\begin{array}{l}146.1 \\
146.1 \\
146.1\end{array}$ & $\begin{array}{l}18 \text { healthy subjects } \\
\text { (10 men and } 8 \text { women) }\end{array}$ & $\begin{array}{l}\text { Hesperetin glucuronides and } \\
\text { sulfates metabolites }\end{array}$ & $\begin{array}{l}2.2 \pm 0.3 \\
4.3 \pm 0.9 \\
5.4 \pm 0.8\end{array}$ & [134] \\
\hline 400-760 mL commercial OJ & $206.6 \pm 42.6$ & $\begin{array}{l}8 \text { healthy subjects } \\
\text { ( } 3 \text { men and } 5 \text { women) }\end{array}$ & Total hesperetin metabolites & $5.3 \pm 3.1$ & [135] \\
\hline $\begin{array}{l}500 \mathrm{~mL} \text { commercial OJ } \\
1000 \mathrm{~mL} \text { commercial OJ }\end{array}$ & $\begin{array}{c}180.3 \pm 6.1 \\
360.6 \pm 12.1\end{array}$ & 5 healthy men & Total hesperetin metabolites & $\begin{array}{l}4.3 \pm 1.2 \\
6.4 \pm 1.3\end{array}$ & [136] \\
\hline \multirow[t]{2}{*}{$500 \mathrm{~mL}$ commercial OJ } & 250 & $\begin{array}{l}10 \text { males in } \\
\text { trained conditions }\end{array}$ & $\begin{array}{l}\text { Hesperetin glucuronides and } \\
\text { sulfates } \\
\text { metabolites/catabolites }\end{array}$ & $3.8 \pm 2.3 / 51$ & [30] \\
\hline & & $\begin{array}{l}10 \text { males in } \\
\text { detrained conditions }\end{array}$ & & $4.8 \pm 2.8 / 59$ & \\
\hline $250 \mathrm{~mL}$ pulp enriched OJ & 348 & $\begin{array}{l}12 \text { healthy subjects } \\
(6 \text { men and } 6 \text { women })\end{array}$ & $\begin{array}{l}\text { Hesperetin glucuronides and } \\
\text { sulfates } \\
\text { metabolites/catabolites }\end{array}$ & $17.5 \pm 2.0 / 26.2$ & [137] \\
\hline $400 \mathrm{~g}$ orange fruit & $1477 \pm 88$ & 11 healthy subjects & $\begin{array}{c}\text { Total hesperetin } \\
\text { metabolites/catabolites }\end{array}$ & $1.5 \pm 0.5 / 20.3$ & [31] \\
\hline $719 \mathrm{~g}$ commercial OJ & $636 \pm 17$ & & & $2.9 \pm 1.1 / 40.4$ & \\
\hline $150 \mathrm{~g}$ orange fruit & $130.6 \pm 29.0$ & $\begin{array}{l}20 \text { healthy subjects } \\
\text { (10 men and } 10 \text { women) }\end{array}$ & Total hesperetin metabolites & $4.3 \pm 3.4$ & [138] \\
\hline $300 \mathrm{~g}$ commercial orange fruit & $117.7 \pm 13.3$ & & & $4.6 \pm 3.1$ & \\
\hline $\begin{array}{l}400 \mathrm{~mL} \text { commercial OJ } \\
400 \mathrm{~mL} \text { commercial OI }\end{array}$ & $191.5 \pm 2.0$ & $\begin{array}{l}10 \text { healthy subjects } \\
(5 \text { men and } 5 \text { women) }\end{array}$ & Hesperetin glucuronides & $\begin{array}{l}5.4 \pm 1.2 \\
1.7 \pm 0.4\end{array}$ & [139] \\
\hline $400 \mathrm{~mL}$ commercial OJ & $352.8 \pm 5.2$ & 10 healthy subiects) & Hesneretin olucuronides & $1.7 \pm 0.4$ & \\
\hline $\begin{array}{l}400 \mathrm{~mL} \text { pulp enriched OJ } \\
400 \mathrm{~mL} \text { OI with flavanone extract }\end{array}$ & $461.0 \pm 2.0$ & $\begin{array}{l}10 \text { healthy subjects } \\
(5 \text { men and } 5 \text { women })\end{array}$ & & $\begin{array}{l}1.0 \pm 0.5 \\
4.6 \pm 1.0\end{array}$ & [139] \\
\hline $\begin{array}{l}400 \mathrm{~mL} \text { OJ with flavanone extract } \\
400 \mathrm{~mL} \text { water with flavanone extract }\end{array}$ & $\begin{array}{c}722.6 \pm 10.5 \\
339.7 \pm 2.0\end{array}$ & & & $\begin{array}{l}4.6 \pm 1.0 \\
8.9 \pm 2.9\end{array}$ & \\
\hline $\begin{array}{c}\text { Commercial OJ } \\
\text { Commercial OJ supplemented } \\
\text { with hesperidin }\end{array}$ & $\begin{array}{l}100.0 \\
314.7\end{array}$ & $\begin{array}{l}16 \text { healthy subjects } \\
\text { ( } 8 \text { men and } 8 \text { women) }\end{array}$ & Total hesperetin metabolites & $\begin{array}{l}4.6 \pm 1.8 \\
8.9 \pm 3.8\end{array}$ & [27] \\
\hline $\begin{array}{c}250 \mathrm{~mL} \text { commercial OJ } \\
250 \mathrm{~mL} \text { commercial OJ and } 150 \mathrm{~mL} \text { full } \\
\text { fat yogurt }\end{array}$ & $\begin{array}{l}168 \\
168\end{array}$ & $\begin{array}{l}8 \text { healthy subjects } \\
\text { (4 men and } 4 \text { women) }\end{array}$ & $\begin{array}{l}\text { Hesperetin glucuronides and } \\
\text { sulfates }\end{array}$ & $\begin{array}{l}6.3 \pm 2.0 \\
6.4 \pm 2.0\end{array}$ & [140] \\
\hline $\begin{array}{c}400 \mathrm{~mL} \text { hand squeezed OJ } \\
400 \mathrm{~mL} \text { high pressure homogenized OJ } \\
400 \mathrm{~mL} \text { pasteurized OJ }\end{array}$ & $\begin{array}{l}62.0 \\
169.6 \\
184.9\end{array}$ & $\begin{array}{l}18 \text { healthy subjects } \\
\text { (10 men and } 8 \text { women) }\end{array}$ & $\begin{array}{l}\text { Hesperetin glucuronides and } \\
\text { sulfates }\end{array}$ & $\begin{array}{l}8.1 \pm 1.4 \\
4.8 \pm 1.1 \\
3.3 \pm 0.5\end{array}$ & [141] \\
\hline $786 \mathrm{~mL}$ processed OJ & $199.2 \pm 60.8$ & $\begin{array}{l}24 \text { healthy subjects } \\
\text { (12 men and } 12 \text { women) }\end{array}$ & $\begin{array}{l}\text { Hesperetin glucuronides } \\
\text { and sulfates }\end{array}$ & $4.1 \pm 3.3$ & [142] \\
\hline $786 \mathrm{~mL}$ fresh OJ & $60.8 \pm 5.2$ & & & $3.8 \pm 2.2$ & \\
\hline
\end{tabular}




\subsection{Factors Affecting Hesperidin Bioavailability}

\subsubsection{Microbiota Composition and $\alpha$-L-Rhamnosidase Activity}

The low bioavailability of hesperidin has been attributed to the sugar moiety (the rutinose disaccharide) conjugated to the hesperetin molecule, which hampers absorption in the small intestine [27,143], leading to the vast majority of hesperidin ingested having to be metabolized in the colon by the $\alpha$-rhamnosidase and the $\beta$-glucosidase activity of intestinal microbiota to form hesperetin, its aglycone form [144]. It has been described that $\alpha$-rhamnosidase is the limiting step of the formation of hesperetin due to low levels of this enzymatic activity in the intestinal microbiota [130]. Thus, it is conceivable that intestinal microflora composition may have a large impact on hesperidin bioavailability due to variations in the activity of the $\alpha$-rhamnosidase enzymes. Interestingly, a high negative relationship has been observed between excretion levels of hesperidin metabolites and excretion levels of hesperetin catabolites from the intestinal microbiota, such as HMPPA [31], indicating that the microbiota of high and low hesperidin excretors have different activities associated with hesperidin metabolism. However, despite the potential effects of $\alpha$-rhamnosidase activity on hesperidin bioavailability and its biological effects, there are no available studies to clearly demonstrate these effects. Therefore, further in vivo studies in humans are needed to clarify the effect of $\alpha$-rhamnosidase activity on the bioavailability of hesperidin.

\subsubsection{Stereochemical Properties of Hesperidin}

The hesperidin molecule has a chiral carbon that generates two diastereoisomers, $-\mathrm{R}$ and $-\mathrm{S}$; however, in nature, the predominant form is the $-S$ diastereoisomer [145]. Hesperidin is present in the fresh fruit products, including OJ, in a S:R ratio of at least 92:8 in favor of the 2S-epimer [145].

The stereochemical properties of flavonoids have been reported to influence their bioavailability [146]. Specifically for hesperidin, the effects of its stereochemical properties on plasma and urinary kinetics of hesperetin have been described [147,148], and may thus affect both the intestinal metabolism and transport of hesperetin as well as its biological effects [149]. In an in vivo study, the administration of racemic hesperetin to rats demonstrated that $\mathrm{R}$-hesperetin had a significant 3.3-fold higher area under the serum concentration-time curve (AUC), a 1.9-fold longer half-life, and a 2.3-fold higher cumulative urinary excretion compared to S-hesperetin [148]. Furthermore, Yez et al. observed that oral administration of racemic hesperidin to a single rat revealed a slightly $(\sim 15 \%)$ increased cumulative $24 \mathrm{~h}$ urinary excretion of R-hesperetin compared to S-hesperetin [147]. In an in vitro study with human small intestinal microsomes, the authors observed a higher affinity and capacity towards S-hesperetin resulting in an overall 5.2-fold higher catalytic efficiency for the formation of S-hesperetin glucuronides as compared to R-hesperetin glucuronides [149]. This is important because although hesperidin naturally exists mainly as the 2S-epimer, which upon intake is subsequently transformed into S-hesperetin, practically all research on hesperidin and hesperetin using "pure" compounds is on racemic mixtures, because the vast majority of current hesperidin products are commercially available as a mixture of both diastereoisomers [149]. Due to these scenarios, there are companies that are investigating producing hesperidin products consisting of $100 \%$ S-hesperidin.

\subsubsection{Food Matrix and Food Processing}

The bioavailability of hesperidin can be influenced by the food matrix in which it is consumed. In this sense, the term bioaccessibility refers to the fraction of a compound that is released from its matrix in the gastrointestinal tract and thus becomes available for intestinal absorption. In a clinical study by Mullen et al., the impact of a full-fat yogurt on the bioavailability of OJ flavanones was investigated. Hesperidin levels in urine and plasma were measured after the consumption of $250 \mathrm{~mL}$ of OJ, with and without $150 \mathrm{~mL}$ of full-fat yogurt. The results demonstrated that although the quantity of flavanone metabolites excreted $0-5 \mathrm{~h}$ after $\mathrm{OJ}$ ingestion was significantly reduced by yogurt, over the full 0-24 $\mathrm{h}$ urine collection period, the amounts excreted were not affected by the addition of yogurt to the drink. The authors concluded that the full-fat yogurt had little effect on the bioavailability of the OJ flavanones probably due to the low amount of fats in the yogurt [140]. 
Related to the food matrix factor, the solubility of a given metabolite is a requirement to enter the systemic circulation and exert a physiological effect. For hesperidin, a low solubility has been described, especially in aqueous systems [150]. In a crossover clinical study with 10 volunteers, Vallejo et al. evaluated the effect of hesperidin concentration and solubility of orange beverages on its bioavailability. Participants consumed five different beverages with different hesperidin concentrations. The results showed that hesperidin excretion and maximal concentration (Cmax) in plasma were correlated with the soluble hesperidin concentration in juice, whereas no correlation was observed with the total hesperidin intake. The authors concluded that the solubility of hesperidin in the juice was a key factor for the bioavailability [139].

In a study that evaluated the in vitro bioaccessibility of hesperidin in different matrix sources, it was observed that the bioaccessibility of hesperidin increased significantly upon juice extraction compared to orange segments [151]. The authors concluded that the lower flavonoid levels in OJ as compared to orange segments might be less relevant regarding their intestinal absorption, because low flavonoid solubility may be the limiting factor [151]. In a clinical study evaluating the bioavailability of hesperidin from orange fruit and from OJ, despite the higher hesperidin dose delivered with the orange fruit, urinary hesperetin excretion did not differ from that observed after the consumption of OJ, suggesting that release, absorption, and metabolism of dietary flavanones are saturated when intake exceeds a certain limit. Another possible explanation was the entrapment of hesperidin within the fiber-rich matrix of orange fruit [31]. Supported by these findings, it is assumed that the higher hesperidin level in orange fruits compared to OJ offers only a limited nutritional benefit. Nevertheless, in another clinical study by Brett et al., no differences were observed in bioavailability, based on total urinary hesperetin excretion of human subjects after consumption of orange fruit and OJ matrices [138].

Hesperidin in OJ exists as both soluble in the juice serum and precipitated in the juice cloud. It has been suggested that hesperidin associated with the juice cloud may be available to enzymatic action in the gastrointestinal tract at different rates than the soluble form [152]. Furthermore, it has been demonstrated that the distribution of hesperidin in $\mathrm{OJ}$ is influenced by commercial juice processing and storage techniques [141,152-154], with total concentrations of soluble hesperidin being higher in hand squeezed OJ than in commercially processed OJ [141,153,154], while freezing and cold storage of processed juice decreases hesperidin solubility [152]. However, a clinical study that measured the bioavailability of hesperidin after single doses of hand-squeezed OJ or commercially processed OJ in healthy humans showed no statistically significant difference in the percentage of urinary-excreted hesperidin between both different styles of OJ products [142], suggesting that absorption of the OJ flavanones was not appreciably influenced by the distributions of soluble and precipitated forms [142].

Efforts have been made to overcome the drawbacks of poorly water-soluble hesperidin to enhance its absorption. In this sense, the use of nanotechnology to encapsulate hesperidin represents a promising strategy to circumvent hesperidin physicochemical and bioavailability constraints, since it might enhance hesperidin's solubility and absorption [155]. In fact, in a clinical study that evaluated the effect of hesperidin encapsulation and particle size reduction on hesperidin bioavailability, it was observed that both hesperidin micronization and encapsulation increased hesperidin bioavailability compared to conventional hesperidin. The authors concluded that particle size reduction and hesperidin dispersion are two ways to enhance its bioavailability. Furthermore, the results suggested that micronization can be used to overcome the need for gut microbiota $\alpha$-rhamnosidase hydrolysis by enhancing hesperidin solubility and reducing particle size to facilitate the interaction with intestinal cells and gut microbiota [134].

In recent years, several delivery nanocarrier-based formulations have been developed to modulate the release of bioactive compounds, including polyphenols such as catechins, quercetin, eugenol, epigallocatechin, curcumin, and tea polyphenols, demonstrating improvements in the solubility of these bioactive molecules, improving their bioavailability, absorption, and biological effects [155,156]. In this sense, in the past years, nanosuspensions, polymeric nanoparticles, nanocapsules, nanofibrous scaffolds, nanoemulsions, and nanoliposomes, among others, have been investigated to deliver polyphenols and improve its bioavailability and bioactivity $[155,157]$. However, concerns related to 
the nanoencapsulation of polyphenols have been reported, due to their varying structures, solubility, and fast oxidation under basic conditions [155]. Furthermore, various wall materials, preparation methods, encapsulation processes, and release mechanisms, as well as several main factors including $\mathrm{pH}$ values, temperatures, particle sizes, and additives, can strongly influence the encapsulation processes and efficacy [158]. Therefore, efforts should be made to evaluate the effects of nanoencapsulation on the metabolism, bioavailability, and efficacy of hesperidin.

\section{Future Remarks}

Large interindividual variability regarding hesperidin bioavailability may explain some of the discrepancies observed among the results from different clinical trials reporting the effects of hesperidin on CVD risk factors. Volunteer stratification into high, medium, and low urinary metabolites excretors or metabotypes may explain, at least partly, this large interindividual variability. In turn, this interindividual variability can be determined by several factors, such as age, sex, genetics, or gut microbiota. Personalized nutrition is a way to address interindividual differences, since it aims to deliver nutritional intervention or nutritional advice suited to the particular characteristics of each person, in order to maximize the beneficial effects of diet and dietary compounds on health [159].

Two approaches to reach personalized nutrition have been defined. Thus, personalized nutrition, or also named individually tailored nutrition, attempts to deliver nutritional intervention or nutritional advice suited to each individual, whereas stratified nutrition, or tailored nutrition, attempts to group individuals with shared characteristics and to deliver nutritional intervention or nutritional advice that is suited to each group. Tailored nutrition has been based primarily on the analysis of genetic variations to cluster individuals according to genetic set up. However, the benefits for public health have been limited [160]. In this context, the use of metabolomics and metabolite profile analysis allows one to tackle personalized nutrition thoroughly, since the interaction and outcome of different factors, such as genes, diet, microbiota, and environmental factors, are included in metabolite profiles, provide complete information on the biological processes of the organism [161]. The concept of metabolic phenotype, or metabotype, refers to the combination of specific metabolites to classify individuals into groups or clusters based on a similar metabolic phenotype. In the context of nutrition, metabolic phenotyping allows one to examine the response of individuals to dietary interventions and to deliver dietary advice adapted to individuals depending on their specific metabotype [161].

As an example of the use of metabotyping for individual clustering to personalize nutrition, in a clinical study, the authors observed that individuals may be classified based on the metabotype associated with the ellagic acid polyphenol (metabotype A, B, or 0) according to the metabolite profile excreted in their urine after ingestion of this polyphenol [162,163]. By this classification, supplementation of the diet with a pomegranate extract, which is rich in ellagic acid, was able to lower blood cholesterol levels in those individuals with a specific profile of metabolites of the metabotype $B$, while no significant differences on the cholesterol concentration were observed when the effects were analyzed in all the study subjects. In addition, the distribution of these metabotypes among the population was different depending on their state of health, with a higher frequency of metabotype B in obese people and those with MetS [162].

Given that the intestinal microbiota plays an important role in hesperidin metabolism and absorption through $\alpha$-rhamnosidase activity, and that the activity of this enzyme can vary considerably depending on the composition of the microbiota, the metabotype associated with hesperidin consumption will be closely linked to the microbial profile. However, the relation between the hesperidin metabotype (low, medium, or high urine metabolites excretors) and $\alpha$-rhamnosidase activity has not been studied in humans. In addition, these different metabotypes have not been associated with specific enterotypes (e.g., a profile of the characteristic microbiota), which would help to explain the role of the microbiota in the bioavailability of hesperidin.

In conclusion, animal and human studies are necessary to clarify the relationship between the composition of the intestinal microbiota, the activity of $\alpha$-rhamnosidase, the metabotypes of hesperidin 
consumption, and the effects of this flavonoid on human health. Furthermore, clinical trials to evaluate the beneficial effects of hesperidin consumption on health should be considered, as well as the classification of individuals according to metabotypes.

Author Contributions: A.M.-C., J.T. and C.D.-C. wrote the manuscript; C.D.-C., A.C. (Anna Crescenti), A.M.-C., J.T., X.E. and A.C. (Antoni Caimari) participated in the discussion; and A.C. (Antoni Caimari), J.M.D.B., X.E., and A.C. (Anna Crescenti) revised the manuscript. All authors have read and agreed to the published version of the manuscript.

Funding: This work was financially supported by the Catalan Government through the funding grant ACCIÓ-Eurecat, by the Centre for the Development of Industrial Technology (CDTI) of the Spanish Ministry of Science and Innovation under grant agreement: TECNOMIFOOD project (CER-20191010) and by the European Union's Horizon 2020 Research and Innovation Programme under grant agreement: Preventomics project-No 818318.

Conflicts of Interest: The authors declare no conflict of interest.

\section{References}

1. World Health Organization (WHO). A Global Brief on Hypertension: Silent Killer, Global Public Health Crisis: World Health Day 2013. Available online: https://www.who.int/publications-detail/a-global-brief-onhypertension-silent-killer-global-public-health-crisis-world-health-day-2013 (accessed on 12 March 2020).

2. Roberts, C.K.; Hevener, A.L.; Barnard, R.J. Metabolic syndrome and insulin resistance: Underlying causes and modification by exercise training. Compr. Physiol. 2013, 3, 1-58. [PubMed]

3. Peluso, I.; Romanelli, L.; Palmery, M. Interactions between prebiotics, probiotics, polyunsaturated fatty acids and polyphenols: Diet or supplementation for metabolic syndrome prevention? Int. J. Food Sci. Nutr. 2014, 65, 259-267. [CrossRef] [PubMed]

4. Asrih, M.; Jornayvaz, F.R. Metabolic syndrome and nonalcoholic fatty liver disease: Is insulin resistance the link? Mol. Cell. Endocrinol. 2015, 418, 55-65. [CrossRef] [PubMed]

5. Mendis, S.; Puska, P.; Norrving, B. Global Atlas on Cardiovascular Disease Prevention and Control; World Health Organization: Geneva, Switzerland, 2011; pp. 2-14.

6. Alissa, E.M.; Ferns, G.A. Dietary fruits and vegetables and cardiovascular diseases risk. Crit. Rev. Food Sci. Nutr. 2017, 57, 1950-1962. [CrossRef] [PubMed]

7. Kahleova, H.; Salas-Salvadó, J.; Rahelić, D.; Kendall, C.W.C.; Rembert, E.; Sievenpiper, J.L. Dietary patterns and cardiometabolic outcomes in diabetes: A summary of systematic reviews and meta-analyses. Nutrients 2019, 11, 2209. [CrossRef]

8. Mahmoud, A.M.; Hernández Bautista, R.J.; Sandhu, M.A.; Hussein, O.E. Beneficial effects of citrus flavonoids on cardiovascular and metabolic health. Oxid. Med. Cell. Longev. 2019, 2019. [CrossRef]

9. Corrêa, T.A.F.; Rogero, M.M.; Hassimotto, N.M.A.; Lajolo, F.M. The Two-Way Polyphenols-Microbiota Interactions and Their Effects on Obesity and Related Metabolic Diseases. Front. Nutr. 2019, 6, 188. [CrossRef]

10. Williamson, G. The role of polyphenols in modern nutrition. Nutr. Bull. 2017, 42, 226-235. [CrossRef]

11. Del Rio, D.; Rodriguez-Mateos, A.; Spencer, J.P.E.; Tognolini, M.; Borges, G.; Crozier, A. Dietary (poly)phenolics in human health: Structures, bioavailability, and evidence of protective effects against chronic diseases. Antioxid. Redox Signal. 2013, 18, 1818-1892. [CrossRef]

12. Zamora-Ros, R.; Andres-Lacueva, C.; Lamuela-Raventós, R.M.; Berenguer, T.; Jakszyn, P.; Barricarte, A.; Ardanaz, E.; Amiano, P.; Dorronsoro, M.; Larrañaga, N.; et al. Estimation of Dietary Sources and Flavonoid Intake in a Spanish Adult Population (EPIC-Spain). J. Am. Diet. Assoc. 2010, 110, 390-398. [CrossRef]

13. European Fruit Juice Association (AIJN). Liquid Fruit Market Report; European Fruit Juice Association: Brussels, Belgium, 2018.

14. Erlund, I. Review of the flavonoids quercetin, hesperetin, and naringenin. Dietary sources, bioactivities, bioavailability, and epidemiology. Nutr. Res. 2004, 24, 851-874. [CrossRef]

15. Khan, M.K.; Zill-E-Huma; Dangles, O. A comprehensive review on flavanones, the major citrus polyphenols. J. Food Compos. Anal. 2014, 33, 85-104. [CrossRef]

16. Tomas-Barberan, F.A.; Clifford, M.N. Flavanones, chalcones and dihydrochalcones-Nature, occurrence and dietary burden. J. Sci. Food Agric. 2000, 80, 1073-1080. [CrossRef] 
17. Hajialyani, M.; Farzaei, M.H.; Echeverría, J.; Nabavi, S.M.; Uriarte, E.; Eduardo, S.S. Hesperidin as a neuroprotective agent: A review of animal and clinical evidence. Molecules 2019, 24, 648. [CrossRef] [PubMed]

18. Barreca, D.; Gattuso, G.; Bellocco, E.; Calderaro, A.; Trombetta, D.; Smeriglio, A.; Laganà, G.; Daglia, M.; Meneghini, S.; Nabavi, S.M. Flavanones: Citrus phytochemical with health-promoting properties. BioFactors 2017, 43, 495-506. [CrossRef]

19. Kumar, S.; Pandey, A.K.; Lu, K.P.; Sastre, J. Chemistry and Biological Activities of Flavonoids: An Overview. Sci. World J. 2013, 2013, 16. [CrossRef] [PubMed]

20. Li, C.; Schluesener, H. Health-promoting effects of the citrus flavanone hesperidin. Crit. Rev. Food Sci. Nutr. 2017, 57, 613-631. [CrossRef]

21. Kim, J.; Wie, M.B.; Ahn, M.; Tanaka, A.; Matsuda, H.; Shin, T. Benefits of hesperidin in central nervous system disorders: A review. Anat. Cell Biol. 2019, 52, 369-377. [CrossRef]

22. Dhanya, R.; Jayamurthy, P. In vitro evaluation of antidiabetic potential of hesperidin and its aglycone hesperetin under oxidative stress in skeletal muscle cell line. Cell Biochem. Funct. 2020. [CrossRef]

23. Xuguang, H.; Aofei, T.; Tao, L.; Longyan, Z.; Weijian, B.; Jiao, G. Hesperidin ameliorates insulin resistance by regulating the IRS1-GLUT2 pathway via TLR4 in HepG2 cells. Phyther. Res. PTR 2019, 33, 1697-1705. [CrossRef]

24. Yamamoto, M.; Suzuki, A.; Hase, T. Short-term effects of glucosyl hesperidin and hesperetin on blood pressure and vascular endothelial function in spontaneously hypertensive rats. J. Nutr. Sci. Vitaminol. (Tokyo) 2008, 54, 95-98. [CrossRef] [PubMed]

25. Wang, X.; Hasegawa, J.; Kitamura, Y.; Wang, Z.; Matsuda, A.; Shinoda, W.; Miura, N.; Kimura, K. Effects of hesperidin on the progression of hypercholesterolemia and fatty liver induced by high-cholesterol diet in rats. J. Pharmacol. Sci. 2011, 117, 129-138. [CrossRef] [PubMed]

26. Yamamoto, M.; Jokura, H.; Hashizume, K.; Ominami, H.; Shibuya, Y.; Suzuki, A.; Hase, T.; Shimotoyodome, A. Hesperidin metabolite hesperetin-7-O-glucuronide, but not hesperetin-3'-O-glucuronide, exerts hypotensive, vasodilatory, and anti-inflammatory activities. Food Funct. 2013, 4, 1346-1351. [CrossRef] [PubMed]

27. Nielsen, I.L.F.; Chee, W.S.S.; Poulsen, L.; Offord-Cavin, E.; Rasmussen, S.E.; Frederiksen, H.; Enslen, M.; Barron, D.; Horcajada, M.-N.; Williamson, G. Bioavailability Is Improved by Enzymatic Modification of the Citrus Flavonoid Hesperidin in Humans: A Randomized, Double-Blind, Crossover Trial. J. Nutr. 2006, 136, 404-408. [CrossRef] [PubMed]

28. Piñuel, L.; Breccia, J.D.; Guisán, J.M.; López-Gallego, F. Production of hesperetin using a covalently multipoint immobilized diglycosidase from acremonium sp. DSM24697. J. Mol. Microbiol. Biotechnol. 2013, 23, 410-417. [CrossRef]

29. Kobayashi, S.; Konishi, Y. Transepithelial transport of flavanone in intestinal Caco-2 cell monolayers. Biochem. Biophys. Res. Commun. 2008, 368, 23-29. [CrossRef]

30. Pereira-Caro, G.; Polyviou, T.; Ludwig, I.A.; Nastase, A.M.; Moreno-Rojas, J.M.; Garcia, A.L.; Malkova, D.; Crozier, A. Bioavailability of orange juice (poly)phenols: The impact of short-term cessation of training by male endurance athletes. Am. J. Clin. Nutr. 2017, 106, 791-800. [CrossRef]

31. Aschoff, J.K.; Riedl, K.M.; Cooperstone, J.L.; Högel, J.; Bosy-Westphal, A.; Schwartz, S.J.; Carle, R.; Schweiggert, R.M. Urinary excretion of Citrus flavanones and their major catabolites after consumption of fresh oranges and pasteurized orange juice: A randomized cross-over study. Mol. Nutr. Food Res. 2016, 60, 2602-2610. [CrossRef]

32. Ozdal, T.; Sela, D.A.; Xiao, J.; Boyacioglu, D.; Chen, F.; Capanoglu, E. The reciprocal interactions between polyphenols and gut microbiota and effects on bioaccessibility. Nutrients 2016, 8, 78. [CrossRef]

33. Alvarez, C.A.; Lingvay, I.; Vuylsteke, V.; Koffarnus, R.L.; Mcguire, D.K. Cardiovascular risk in diabetes mellitus: Complication of the disease or of antihyperglycemic medications. Clin. Pharmacol. Ther. 2015, 98, 145-161. [CrossRef]

34. Zhang, J.; Sun, C.; Yan, Y.; Chen, Q.; Luo, F.; Zhu, X.; Li, X.; Chen, K. Purification of naringin and neohesperidin from Huyou (Citrus changshanensis) fruit and their effects on glucose consumption in human HepG2 cells. Food Chem. 2012, 135, 1471-1478. [CrossRef] [PubMed]

35. Irshad, Z.; Xue, M.; Ashour, A.; Larkin, J.R.; Thornalley, P.J.; Rabbani, N. Activation of the unfolded protein response in high glucose treated endothelial cells is mediated by methylglyoxal. Sci. Rep. 2019, 9, 7889. [CrossRef] [PubMed] 
36. Akiyama, S.; Katsumata, S.-I.; Suzuki, K.; Ishimi, Y.; Wu, J.; Uehara, M. Dietary hesperidin exerts hypoglycemic and hypolipidemic effects in streptozotocin-induced marginal type 1 diabetic rats. J. Clin. Biochem. Nutr. 2010, 46, 87-92. [CrossRef] [PubMed]

37. Kumar, B.; Gupta, S.K.; Srinivasan, B.P.; Nag, T.C.; Srivastava, S.; Saxena, R. Hesperetin ameliorates hyperglycemia induced retinal vasculopathy via anti-angiogenic effects in experimental diabetic rats. Vascul. Pharmacol. 2012, 57, 201-207. [CrossRef]

38. Visnagri, A.; Kandhare, A.D.; Chakravarty, S.; Ghosh, P.; Bodhankar, S.L. Hesperidin, a flavanoglycone attenuates experimental diabetic neuropathy via modulation of cellular and biochemical marker to improve nerve functions. Pharm. Biol. 2014, 52, 814-828. [CrossRef] [PubMed]

39. Hanchang, W.; Khamchan, A.; Wongmanee, N.; Seedadee, C. Hesperidin ameliorates pancreatic $\beta$-cell dysfunction and apoptosis in streptozotocin-induced diabetic rat model. Life Sci. 2019, 235, 116858. [CrossRef] [PubMed]

40. Sundaram, R.; Nandhakumar, E.; Haseena Banu, H. Hesperidin, a citrus flavonoid ameliorates hyperglycemia by regulating key enzymes of carbohydrate metabolism in streptozotocin-induced diabetic rats. Toxicol. Mech. Methods 2019, 29, 644-653. [CrossRef]

41. Dokumacioglu, E.; Iskender, H.; Sen, T.M.; Ince, I.; Dokumacioglu, A.; Kanbay, Y.; Erbas, E.; Saral, S. The Effects of Hesperidin and Quercetin on Serum Tumor Necrosis Factor-Alpha and Interleukin-6 Levels in Streptozotocin-induced Diabetes Model. Pharmacogn. Mag. 2018, 14, 167-173.

42. Jung, U.J.; Lee, M.-K.; Jeong, K.-S.; Choi, M.-S. The hypoglycemic effects of hesperidin and naringin are partly mediated by hepatic glucose-regulating enzymes in C57BL/KsJ-db/db mice. J. Nutr. 2004, 134, 2499-2503. [CrossRef]

43. Jung, U.J.; Lee, M.-K.; Park, Y.B.; Kang, M.A.; Choi, M.-S. Effect of citrus flavonoids on lipid metabolism and glucose-regulating enzyme mRNA levels in type-2 diabetic mice. Int. J. Biochem. Cell Biol. 2006, 38, 1134-1145. [CrossRef]

44. Akiyama, S.; Katsumata, S.; Suzuki, K.; Nakaya, Y.; Ishimi, Y.; Uehara, M. Hypoglycemic and hypolipidemic effects of hesperidin and cyclodextrin-clathrated hesperetin in Goto-Kakizaki rats with type 2 diabetes. Biosci. Biotechnol. Biochem. 2009, 73, 2779-2782. [CrossRef] [PubMed]

45. Mahmoud, A.M.; Ashour, M.B.; Abdel-Moneim, A.; Ahmed, O.M. Hesperidin and naringin attenuate hyperglycemia-mediated oxidative stress and proinflammatory cytokine production in high fat fed/streptozotocin-induced type 2 diabetic rats. J. Diabetes Complicat. 2012, 26, 483-490. [CrossRef] [PubMed]

46. Jia, S.; Hu, Y.; Zhang, W.; Zhao, X.; Chen, Y.; Sun, C.; Li, X.; Chen, K. Hypoglycemic and hypolipidemic effects of neohesperidin derived from Citrus aurantium L. in diabetic KK-A(y) mice. Food Funct. 2015, 6, 878-886. [CrossRef] [PubMed]

47. Sun, Y.-Z.; Chen, J.-F.; Shen, L.-M.; Zhou, J.; Wang, C.-F. Anti-atherosclerotic effect of hesperidin in LDLr-/mice and its possible mechanism. Eur. J. Pharmacol. 2017, 815, 109-117. [CrossRef]

48. Mayneris-Perxachs, J.; Alcaide-Hidalgo, J.M.; de la Hera, E.; del Bas, J.M.; Arola, L.; Caimari, A. Supplementation with biscuits enriched with hesperidin and naringenin is associated with an improvement of the Metabolic Syndrome induced by a cafeteria diet in rats. J. Funct. Foods 2019, 61, 103504. [CrossRef]

49. Rehman, K.; Munawar, S.M.; Akash, M.S.H.; Buabeid, M.A.; Chohan, T.A.; Tariq, M.; Jabeen, K.; Arafa, E.-S.A. Hesperidin improves insulin resistance via down-regulation of inflammatory responses: Biochemical analysis and in silico validation. PLOS ONE 2020, 15, e0227637.

50. Pu, P. Protection mechanisms of hesperidin on mouse with insulin resistance. Zhongguo Zhong Yao Za Zhi 2016, 41, 3290-3295.

51. Wu, H.; Liu, Y.; Chen, X.; Zhu, D.; Ma, J.; Yan, Y.; Si, M.; Li, X.; Sun, C.; Yang, B.; et al. Neohesperidin Exerts Lipid-Regulating Effects in vitro and in vivo via Fibroblast Growth Factor 21 and AMP-Activated Protein Kinase/Sirtuin Type 1/Peroxisome Proliferator-Activated Receptor Gamma Coactivator $1 \alpha$ Signaling Axis. Pharmacology 2017, 100, 115-126. [CrossRef]

52. Yari, Z.; Movahedian, M.; Imani, H.; Alavian, S.M.; Hedayati, M.; Hekmatdoost, A. The effect of hesperidin supplementation on metabolic profiles in patients with metabolic syndrome: A randomized, double-blind, placebo-controlled clinical trial. Eur. J. Nutr. 2019. [CrossRef]

53. Ribeiro, C.; Dourado, G.; Cesar, T. Orange juice allied to a reduced-calorie diet results in weight loss and ameliorates obesity-related biomarkers: A randomized controlled trial. Nutrition 2017, 38, 13-19. [CrossRef] 
54. Lima, A.C.D.; Cecatti, C.; Fidélix, M.P.; Adorno, M.A.T.; Sakamoto, I.K.; Cesar, T.B.; Sivieri, K. Effect of Daily Consumption of Orange Juice on the Levels of Blood Glucose, Lipids, and Gut Microbiota Metabolites: Controlled Clinical Trials. J. Med. Food 2019, 22, 202-210. [CrossRef] [PubMed]

55. Cheraghpour, M.; Imani, H.; Ommi, S.; Alavian, S.M.; Karimi-Shahrbabak, E.; Hedayati, M.; Yari, Z.; Hekmatdoost, A. Hesperidin improves hepatic steatosis, hepatic enzymes, and metabolic and inflammatory parameters in patients with nonalcoholic fatty liver disease: A randomized, placebo-controlled, double-blind clinical trial. Phyther. Res. PTR 2019, 33, 2118-2125. [CrossRef] [PubMed]

56. Homayouni, F.; Haidari, F.; Hedayati, M.; Zakerkish, M.; Ahmadi, K. Hesperidin Supplementation Alleviates Oxidative DNA Damage and Lipid Peroxidation in Type 2 Diabetes: A Randomized Double-Blind Placebo-Controlled Clinical Trial. Phyther. Res. PTR 2017, 31, 1539-1545. [CrossRef] [PubMed]

57. Rizza, S.; Muniyappa, R.; Iantorno, M.; Kim, J.A.; Chen, H.; Pullikotil, P.; Senese, N.; Tesauro, M.; Lauro, D.; Cardillo, C.; et al. Citrus polyphenol hesperidin stimulates production of nitric oxide in endothelial cells while improving endothelial function and reducing inflammatory markers in patients with metabolic syndrome. J. Clin. Endocrinol. Metab. 2011, 96, 782-792. [CrossRef] [PubMed]

58. Salden, B.N.; Troost, F.J.; De Groot, E.; Stevens, Y.R.; Garcés-Rimón, M.; Possemiers, S.; Winkens, B.; Masclee, A.A. Randomized clinical trial on the efficacy of hesperidin $2 \mathrm{~S}$ on validated cardiovascular biomarkers in healthy overweight individuals. Am. J. Clin. Nutr. 2016, 104, 1523-1533. [CrossRef]

59. Constans, J.; Bennetau-Pelissero, C.; Martin, J.-F.; Rock, E.; Mazur, A.; Bedel, A.; Morand, C.; Bérard, A.M. Marked antioxidant effect of orange juice intake and its phytomicronutrients in a preliminary randomized cross-over trial on mild hypercholesterolemic men. Clin. Nutr. 2015, 34, 1093-1100. [CrossRef]

60. Morand, C.; Dubray, C.; Milenkovic, D.; Lioger, D.; Martin, J.F.; Scalbert, A.; Mazur, A. Hesperidin contributes to the vascular protective effects of orange juice: A randomized crossover study in healthy volunteers. Am. J. Clin. Nutr. 2011, 93, 73-80. [CrossRef]

61. Rangel-Huerta, O.D.; Aguilera, C.M.; Martin, M.V.; Soto, M.J.; Rico, M.C.; Vallejo, F.; Tomas-Barberan, F.; Perez-de-la-Cruz, A.J.; Gil, A.; Mesa, M.D. Normal or High Polyphenol Concentration in Orange Juice Affects Antioxidant Activity, Blood Pressure, and Body Weight in Obese or Overweight Adults. J. Nutr. 2015, 145, 1808-1816. [CrossRef]

62. Isomaa, B.; Almgren, P.; Tuomi, T.; Forsén, B.; Lahti, K.; Nissén, M.; Taskinen, M.R.; Groop, L. Cardiovascular morbidity and mortality associated with the metabolic syndrome. Diabetes Care 2001, 24, 683-689. [CrossRef]

63. Stewart, J.; Manmathan, G.; Wilkinson, P. Primary prevention of cardiovascular disease: A review of contemporary guidance and literature. JRSM Cardiovasc. Dis. 2017, 6, 2048004016687211. [CrossRef]

64. Reyes-Soffer, G.; Rondon-Clavo, C.; Ginsberg, H.N. Combination therapy with statin and fibrate in patients with dyslipidemia associated with insulin resistance, metabolic syndrome and type 2 diabetes mellitus. Expert Opin. Pharmacother. 2011, 12, 1429-1438. [CrossRef] [PubMed]

65. Assini, J.M.; Mulvihill, E.E.; Huff, M.W. Citrus flavonoids and lipid metabolism. Curr. Opin. Lipidol. 2013, 24, 34-40. [CrossRef] [PubMed]

66. Xiong, H.; Wang, J.; Ran, Q.; Lou, G.; Peng, C.; Gan, Q.; Hu, J.; Sun, J.; Yao, R.; Huang, Q. Hesperidin: A therapeutic agent for obesity. Drug Des. Devel. Ther. 2019, 13, 3855-3866. [CrossRef] [PubMed]

67. Simpson, E.J.; Mendis, B.; Macdonald, I.A. Orange juice consumption and its effect on blood lipid profile and indices of the metabolic syndrome; a randomised, controlled trial in an at-risk population. Food Funct. 2016, 7, 1884-1891. [CrossRef]

68. Aptekmann, N.P.; Cesar, T.B. Orange juice improved lipid profile and blood lactate of overweight middle-aged women subjected to aerobic training. Maturitas 2010, 67, 343-347. [CrossRef]

69. Mulvihill, E.E.; Huff, M.W. Citrus Flavonoids and the Prevention of Atherosclerosis. Cardiovasc. Hematol. Disord. Targets 2013, 12, 84-91. [CrossRef]

70. Gómez-Zorita, S.; Lasa, A.; Abendaño, N.; Fernández-Quintela, A.; Mosqueda-Solís, A.; Garcia-Sobreviela, M.P.; Arbonés-Mainar, J.M.; Portillo, M.P. Phenolic compounds apigenin, hesperidin and kaempferol reduce in vitro lipid accumulation in human adipocytes. J. Transl. Med. 2017, 15, 237. [CrossRef]

71. Mosqueda-Solís, A.; Lasa, A.; Gómez-Zorita, S.; Eseberri, I.; Picó, C.; Portillo, M.P. Screening of potential anti-adipogenic effects of phenolic compounds showing different chemical structure in 3T3-L1 preadipocytes. Food Funct. 2017, 8, 3576-3586. [CrossRef] 
72. Kim, J.K.; Jeong, H.W.; Kim, A.Y.; Hong, Y.D.; Lee, J.H.; Choi, J.K.; Hwang, J.S. Green satsuma mandarin orange (Citrus unshiu) extract reduces adiposity and induces uncoupling protein expression in skeletal muscle of obese mice. Food Sci. Biotechnol. 2019, 28, 873-879. [CrossRef]

73. Miwa, Y.; Mitsuzumi, H.; Sunayama, T.; Yamada, M.; Okada, K.; Kubota, M.; Chaen, H.; Mishima, Y.; Kibata, M. Glucosyl hesperidin lowers serum triglyceride level in hypertriglyceridemic subjects through the improvement of very low-density lipoprotein metabolic abnormality. J. Nutr. Sci. Vitaminol. (Tokyo) 2005, 51, 460-470. [CrossRef]

74. Demonty, I.; Lin, Y.; Zebregs, Y.E.M.P.; Vermeer, M.A.; van der Knaap, H.C.M.; Jäkel, M.; Trautwein, E.A. The Citrus Flavonoids Hesperidin and Naringin Do Not Affect Serum Cholesterol in Moderately Hypercholesterolemic Men and Women. J. Nutr. 2010, 140, 1615-1620. [CrossRef] [PubMed]

75. Longo, M.; Zatterale, F.; Naderi, J.; Parrillo, L.; Formisano, P.; Raciti, G.A.; Beguinot, F.; Miele, C. Adipose Tissue Dysfunction as Determinant of Obesity-Associated Metabolic Complications. Mol. Sci. 2019, 20, 2358. [CrossRef] [PubMed]

76. Wells, J.C.K. The evolution of human adiposity and obesity: Where did it all go wrong? DMM Dis. Model. Mech. 2012, 5, 595-607. [CrossRef] [PubMed]

77. Serino, A.; Salazar, G. Protective role of polyphenols against vascular inflammation, aging and cardiovascular disease. Nutrients 2019, 11, 53. [CrossRef] [PubMed]

78. Mosqueda-Solís, A.; Sánchez, J.; Portillo, M.P.; Palou, A.; Picó, C. Combination of Capsaicin and Hesperidin Reduces the Effectiveness of Each Compound To Decrease the Adipocyte Size and To Induce Browning Features in Adipose Tissue of Western Diet Fed Rats. J. Agric. Food Chem. 2018, 66, 9679-9689. [CrossRef]

79. Ohara, T.; Muroyama, K.; Yamamoto, Y.; Murosaki, S. Oral intake of a combination of glucosyl hesperidin and caffeine elicits an anti-obesity effect in healthy, moderately obese subjects: A randomized double-blind placebo-controlled trial. Nutr. J. 2016, 15, 6. [CrossRef] [PubMed]

80. Franklin, S.S. Systolic blood pressure: It's time to take control. Am. J. Hypertens. 2004, 17, S49-S54. [CrossRef]

81. Zanchetti, A. Hypertension: Lower or higher blood-pressure targets for high-risk patients? Nat. Rev. Cardiol. 2016, 13, 637-638. [CrossRef]

82. Ohtsuki, K.; Abe, A.; Mitsuzumi, H.; Kondo, M.; Uemura, K.; Iwasaki, Y.; Kondo, Y. Effects of long-term administration of hesperidin and glucosyl hesperidin to spontaneously hypertensive rats. J. Nutr. Sci. Vitaminol. (Tokyo) 2002, 48, 420-422. [CrossRef]

83. Ikemura, M.; Sasaki, Y.; Giddings, J.C.; Yamamoto, J. Preventive effects of hesperidin, glucosyl hesperidin and naringin on hypertension and cerebral thrombosis in stroke-prone spontaneously hypertensive Rats. Phyther. Res. 2012, 26, 1272-1277. [CrossRef]

84. Guirro, M.; Gual-Grau, A.; Gibert-Ramos, A.; Alcaide-Hidalgo, J.M.; Canela, N.; Mayneris-Perxachs, J. Metabolomics Elucidates Dose-Dependent Molecular Beneficial E ff ects of Hesperidin Supplementation in Rats Fed an Obesogenic Diet. Antioxidants 2020, 9, 79. [CrossRef] [PubMed]

85. Wunpathe, C.; Potue, P.; Maneesai, P.; Bunbupha, S.; Prachaney, P.; Kukongviriyapan, U.; Kukongviriyapan, V.; Pakdeechote, P. Hesperidin Suppresses Renin-Angiotensin System Mediated NOX2 Over-Expression and Sympathoexcitation in 2K-1C Hypertensive Rats. Am. J. Chin. Med. 2018, 46, 751-767. [CrossRef] [PubMed]

86. Dobiaš, L.; Petrová, M.; Vojtko, R.; Kristová, V. Long-term Treatment with Hesperidin Improves Endothelium-dependent Vasodilation in Femoral Artery of Spontaneously Hypertensive Rats: The Involvement of NO-synthase and Kv Channels. Phyther. Res. 2016, 1665-1671. [CrossRef] [PubMed]

87. Liu, L.; Xu, D.M.; Cheng, Y.Y. Distinct effects of naringenin and hesperetin on nitric oxide production from endothelial cells. J. Agric. Food Chem. 2008, 56, 824-829. [CrossRef]

88. Pons, Z.; Guerrero, L.; Margalef, M.; Arola, L.; Arola-Arnal, A.; Muguerza, B. Effect of low molecular grape seed proanthocyanidins on blood pressure and lipid homeostasis in cafeteria diet-fed rats. J. Physiol. Biochem. 2014, 70, 629-637. [CrossRef]

89. Wilmsen, P.K.; Spada, D.S.; Salvador, M. Antioxidant activity of the flavonoid hesperidin in chemical and biological systems. J. Agric. Food Chem. 2005, 53, 4757-4761. [CrossRef]

90. Yamamoto, M.; Suzuki, A.; Jokura, H.; Yamamoto, N.; Hase, T. Glucosyl hesperidin prevents endothelial dysfunction and oxidative stress in spontaneously hypertensive rats. Nutrition 2008, 24, 470-476. [CrossRef]

91. Yousefian, M.; Shakour, N.; Hosseinzadeh, H.; Hayes, A.W.; Hadizadeh, F.; Karimi, G. The natural phenolic compounds as modulators of NADPH oxidases in hypertension. Phytomedicine 2019, 55, 200-213. [CrossRef]

92. Asgary, S.; Keshvari, M. Effects of citrus sinensis juice on blood pressure. ARYA Atheroscler. 2013, 9, 98-101. 
93. Homayouni, F.; Haidari, F.; Hedayati, M.; Zakerkish, M.; Ahmadi, K. Blood pressure lowering and anti-inflammatory effects of hesperidin in type 2 diabetes; a randomized double-blind controlled clinical trial. Phyther. Res. 2018, 32, 1073-1079. [CrossRef]

94. Mohammadi, M.; Ramezani-Jolfaie, N.; Lorzadeh, E.; Khoshbakht, Y.; Salehi-Abargouei, A. Hesperidin, a major flavonoid in orange juice, might not affect lipid profile and blood pressure: A systematic review and meta-analysis of randomized controlled clinical trials. Phyther. Res. 2019, 33, 534-545. [CrossRef] [PubMed]

95. Pla-Pagà, L.; Companys, J.; Calderón-Pérez, L.; Llauradó, E.; Solà, R.; Valls, R.M.; Pedret, A. Effects of hesperidin consumption on cardiovascular risk biomarkers: A systematic review of animal studies and human randomized clinical trials. Nutr. Rev. 2019, 77, 845-864. [CrossRef] [PubMed]

96. Jin, M.J.; Kim, U.; Kim, I.S.; Kim, Y.; Kim, D.H.; Han, S.B.; Kwon, O.S.; Yoo, H.H. Effects of gut microflora on pharmacokinetics of hesperidin: A study on non-antibiotic and pseudo-germ-free rats. J. Toxicol. Environ. Heal. A 2010, 73, 1441-1450. [CrossRef] [PubMed]

97. Jiao, Q.; Xu, L.; Jiang, L.; Jiang, Y.; Zhang, J.; Liu, B. Metabolism study of hesperetin and hesperidin in rats by UHPLC-LTQ-Orbitrap MS n. Xenobiotica 2019, 18, 1-27. [CrossRef]

98. Habauzit, V.; Sacco, S.M.; Gil-Izquierdo, A.; Trzeciakiewicz, A.; Morand, C.; Barron, D.; Pinaud, S.; Offord, E.; Horcajada, M.N. Differential effects of two citrus flavanones on bone quality in senescent male rats in relation to their bioavailability and metabolism. Bone 2011, 49, 1108-1116. [CrossRef]

99. Huttenhower, C.; Gevers, D.; Knight, R.; Abubucker, S.; Badger, J.H.; Chinwalla, A.T.; Creasy, H.H.; Earl, A.M.; Fitzgerald, M.G.; Fulton, R.S.; et al. Structure, function and diversity of the healthy human microbiome. Nature 2012, 486, 207-214.

100. Lozupone, C.A.; Stombaugh, J.I.; Gordon, J.I.; Jansson, J.K.; Knight, R. Diversity, stability and resilience of the human gut microbiota. Nature 2012, 489, 220-230. [CrossRef]

101. Lourens-Hattingh, A.; Viljoen, B.C. Yogurt as probiotic carrier food. Int. Dairy J. 2001, 11, 1-17. [CrossRef]

102. Danneskiold-Samsøe, N.B.; Dias de Freitas Queiroz Barros, H.; Santos, R.; Bicas, J.L.; Cazarin, C.B.B.; Madsen, L.; Kristiansen, K.; Pastore, G.M.; Brix, S.; Maróstica Júnior, M.R. Interplay between food and gut microbiota in health and disease. Food Res. Int. 2019, 115, 23-31. [CrossRef]

103. Anhê, F.F.; Nachbar, R.T.; Varin, T.V.; Trottier, J.; Dudonné, S.; Le Barz, M.; Feutry, P.; Pilon, G.; Barbier, O.; Desjardins, Y.; et al. Treatment with camu camu (Myrciaria dubia) prevents obesity by altering the gut microbiota and increasing energy expenditure in diet-induced obese mice. Gut 2019, 68, 453-464. [CrossRef]

104. Chávez-Carbajal, A.; Nirmalkar, K.; Pérez-Lizaur, A.; Hernández-Quiroz, F.; Ramírez-Del-Alto, S.; García-Mena, J.; Hernández-Guerrero, C. Gut microbiota and predicted metabolic pathways in a sample of Mexican women affected by obesity and obesity plus metabolic syndrome. Int. J. Mol. Sci. 2019, 20, 438. [CrossRef] [PubMed]

105. Wan, M.L.Y.; Ling, K.H.; El-Nezami, H.; Wang, M.F. Influence of functional food components on gut health. Crit. Rev. Food Sci. Nutr. 2019, 59, 1927-1936. [CrossRef] [PubMed]

106. Cardona, F.; Andrés-Lacueva, C.; Tulipani, S.; Tinahones, F.J.; Queipo-Ortuño, M.I. Benefits of polyphenols on gut microbiota and implications in human health. J. Nutr. Biochem. 2013, 24, 1415-1422. [CrossRef] [PubMed]

107. Cushnie, T.P.T.; Hamilton, V.E.S.; Chapman, D.G.; Taylor, P.W.; Lamb, A.J. Aggregation of Staphylococcus aureus following treatment with the antibacterial flavonol galangin. J. Appl. Microbiol. 2007, 103, 1562-1567. [CrossRef] [PubMed]

108. Saavedra, M.; Borges, A.; Dias, C.; Aires, A.; Bennett, R.; Rosa, E.; Simões, M. Antimicrobial Activity of Phenolics and Glucosinolate Hydrolysis Products and their Synergy with Streptomycin against Pathogenic Bacteria. Med. Chem. 2010, 6, 174-183. [CrossRef]

109. Tzounis, X.; Vulevic, J.; Kuhnle, G.G.C.; George, T.; Leonczak, J.; Gibson, G.R.; Kwik-Uribe, C.; Spencer, J.P.E. Flavanol monomer-induced changes to the human faecal microflora. Br. J. Nutr. 2008, 99, 782-792. [CrossRef]

110. Masco, L.; Huys, G.; De Brandt, E.; Temmerman, R.; Swings, J. Culture-dependent and culture-independent qualitative analysis of probiotic products claimed to contain bifidobacteria. Int. J. Food Microbiol. 2005, 102, 221-230. [CrossRef]

111. Den Besten, G.; Van Eunen, K.; Groen, A.K.; Venema, K.; Reijngoud, D.J.; Bakker, B.M. The role of short-chain fatty acids in the interplay between diet, gut microbiota, and host energy metabolism. J. Lipid Res. 2013, 54, 2325-2340. [CrossRef] 
112. Liu, Z.; Chen, H.; Li, C. Novel role of hesperidin improve obesity in HFD mice by modulating the composition of the gut microbiota. Gen. Microbiol. 2020. Preprint.

113. Estruel-Amades, S.; Massot-Cladera, M.; Pérez-Cano, F.J.; Franch, À.; Castell, M.; Camps-Bossacoma, M. Hesperidin effects on gut microbiota and gut-associated lymphoid tissue in healthy rats. Nutrients 2019, 11, 324. [CrossRef]

114. Russell, D.A.; Ross, R.P.; Fitzgerald, G.F.; Stanton, C. Metabolic activities and probiotic potential of bifidobacteria. Int. J. Food Microbiol. 2011, 149, 88-105. [CrossRef] [PubMed]

115. Saad, M.J.A.; Santos, A.; Prada, P.O. Linking gut microbiota and inflammation to obesity and insulin resistance. Physiology 2016, 31, 283-293. [CrossRef] [PubMed]

116. Jin, T.; Song, Z.; Weng, J.; Fantus, I.G. Curcumin and other dietary polyphenols: Potential mechanisms of metabolic actions and therapy for diabetes and obesity. Am. J. Physiol. Endocrinol. Metab. 2018, 314, E201-E205. [CrossRef] [PubMed]

117. Tomás-Barberán, F.A.; Selma, M.V.; Espín, J.C. Interactions of gut microbiota with dietary polyphenols and consequences to human health. Curr. Opin. Clin. Nutr. Metab. Care. 2016, 19, 471-476. [CrossRef]

118. Carrera-Quintanar, L.; Roa, R.I.L.; Quintero-Fabián, S.; Sánchez-Sánchez, M.A.; Vizmanos, B.; Ortuño-Sahagún, D. Phytochemicals that influence gut microbiota as prophylactics and for the treatment of obesity and inflammatory diseases. Mediat. Inflamm. 2018, 2018, 1-18. [CrossRef]

119. Dao, M.C.; Clément, K. Gut microbiota and obesity: Concepts relevant to clinical care. Eur. J. Intern. Med. 2018, 48, 18-24. [CrossRef]

120. Cani, P.D.; Van Hul, M.; Lefort, C.; Depommier, C.; Rastelli, M.; Everard, A. Microbial regulation of organismal energy homeostasis. Nat. Metab. 2019, 1, 34-46. [CrossRef]

121. Canfora, E.E.; Meex, R.C.R.; Venema, K.; Blaak, E.E. Gut microbial metabolites in obesity, NAFLD and T2DM. Nat. Rev. Endocrinol. 2019, 15, 261-273. [CrossRef]

122. Al-Assal, K.; Martinez, A.C.; Torrinhas, R.S.; Cardinelli, C.; Waitzberg, D. Gut microbiota and obesity. Clin. Nutr. Exp. 2018, 20, 60-64. [CrossRef]

123. Vrieze, A.; Van Nood, E.; Holleman, F.; Salojärvi, J.; Kootte, R.S.; Bartelsman, J.F.W.M.; Dallinga-Thie, G.M.; Ackermans, M.T.; Serlie, M.J.; Oozeer, R.; et al. Transfer of intestinal microbiota from lean donors increases insulin sensitivity in individuals with metabolic syndrome. Gastroenterology 2012, 143, 913-916. [CrossRef]

124. Cani, P.D.; Bibiloni, R.; Knauf, C.; Neyrinck, A.M.; Delzenne, N.M. Changes in gut microbiota control metabolic diet-induced obesity and diabetes in mice. Diabetes 2008, 57, 1470-1481. [CrossRef] [PubMed]

125. Gérard, P. Gut microbiota and obesity. Cell. Mol. Life Sci. 2016, 73, 147-162. [CrossRef] [PubMed]

126. Meijnikman, A.S.; Gerdes, V.E.; Nieuwdorp, M.; Herrema, H. Evaluating causality of gut microbiota in obesity and diabetes in humans. Endocr. Rev. 2018, 39, 133-153. [CrossRef] [PubMed]

127. Cianci, R.; Pagliari, D.; Piccirillo, C.A.; Fritz, J.H.; Gambassi, G. The microbiota and immune system crosstalk in health and disease. Mediat. Inflamm. 2018, 2018, 10-13. [CrossRef]

128. Stevens, Y.; Van Rymenant, E.; Grootaert, C.; Van Camp, J.; Possemiers, S.; Masclee, A.; Jonkers, D. The intestinal fate of citrus flavanones and their effects on gastrointestinal health. Nutrients 2019, 11, 1464. [CrossRef]

129. Garg, A.; Garg, S.; Zaneveld, L.J.D.; Singla, A.K. Chemistry and pharmacology of the Citrus bioflavonoid hesperidin. Phytother. Res. 2001, 15, 655-669. [CrossRef]

130. Amaretti, A.; Raimondi, S.; Leonardi, A.; Quartieri, A.; Rossi, M. Hydrolysis of the rutinose-conjugates flavonoids rutin and hesperidin by the gut microbiota and bifidobacteria. Nutrients 2015, 7, 2788-2800. [CrossRef]

131. Van Duynhoven, J.; Vaughan, E.E.; Jacobs, D.M.; Kemperman, R.A.; Van Velzen, E.J.J.; Gross, G.; Roger, L.C.; Possemiers, S.; Smilde, A.K.; Doré, J.; et al. Metabolic fate of polyphenols in the human superorganism. Proc. Natl. Acad. Sci. USA 2011, 108, 4531-4538. [CrossRef]

132. Pereira-Caro, G.; Oliver, C.M.; Weerakkody, R.; Singh, T.; Conlon, M.; Borges, G.; Sanguansri, L.; Lockett, T.; Roberts, S.A.; Crozier, A.; et al. Chronic administration of a microencapsulated probiotic enhances the bioavailability of orange juice flavanones in humans. Free Radic. Biol. Med. 2015, 84, 206-214. [CrossRef]

133. Ooi, L.G.; Liong, M.T. Cholesterol-lowering effects of probiotics and prebiotics: A review of in Vivo and in Vitro Findings. Int. J. Mol. Sci. 2010, 11, 2499-2522. [CrossRef] 
134. Tomás-Navarro, M.; Vallejo, F.; Borrego, F.; Tomás-Barberán, F.A. Encapsulation and micronization effectively improve orange beverage flavanone bioavailability in humans. J. Agric. Food Chem. 2014, 62, 9458-9462. [CrossRef] [PubMed]

135. Erlund, I.; Meririnne, E.; Alfthan, G.; Aro, A. Human Nutrition and Metabolism Plasma Kinetics and Urinary Excretion of the Flavanones Naringenin and Hesperetin in Humans after Ingestion of Orange Juice and Grapefruit Juice. J. Nutr. 2001, 131, 235-241. [CrossRef] [PubMed]

136. Manach, C.; Morand, C.; Gil-Izquierdo, A.; Bouteloup-Demange, C.; Rémésy, C. ORIGINAL COMMUNICATION Bioavailability in humans of the flavanones hesperidin and narirutin after the ingestion of two doses of orange juice. Eur. J. Clin. Nutr. 2003, 57, 235-242. [CrossRef] [PubMed]

137. Bao, W.; Bowers, K.; Tobias, D.K.; Olsen, S.F.; Chavarro, J.; Vaag, A.; Kiely, S.A.; Zhang, C. Prepregnancy low-carbohydrate dietary pattern and risk of gestational diabetes mellitus: A prospective cohort study. Am. J. Clin. Nutr. 2014, 99, 1378-1384. [CrossRef]

138. Brett, G.M.; Hollands, W.; Needs, P.W.; Teucher, B.; Dainty, J.R.; Davis, B.D.; Brodbelt, J.S.; Kroon, P.A. Absorption, metabolism and excretion of flavanones from single portions of orange fruit and juice and effects of anthropometric variables and contraceptive pill use on flavanone excretion. Br. J. Nutr. 2009, 101, 664-675. [CrossRef] [PubMed]

139. Vallejo, F.; Larrosa, M.; Escudero, E.; Zafrilla, M.P.; Cerdá, B.; Boza, J.; García-Conesa, M.T.; Espín, J.C.; Tomás-Barberán, F.A. Concentration and solubility of flavanones in orange beverages affect their bioavailability in humans. J. Agric. Food Chem. 2010, 58, 6516-6524. [CrossRef]

140. Mullen, W.; Archeveque, M.A.; Edwards, C.A.; Matsumoto, H.; Crozier, A. Bioavailability and metabolism of orange juice flavanones in humans: Impact of a full-fat yogurt. J. Agric. Food Chem. 2008, 56, 11157-11164. [CrossRef]

141. Tomás-Navarro, M.; Vallejo, F.; Sentandreu, E.; Navarro, J.L.; Tomás-Barberán, F.A. Volunteer stratification is more relevant than technological treatment in orange juice flavanone bioavailability. J. Agric. Food Chem. 2014, 62, 24-27. [CrossRef]

142. Silveira, J.Q.; Cesar, T.B.; Manthey, J.A.; Baldwin, E.A.; Bai, J.; Raithore, S. Pharmacokinetics of flavanone glycosides after ingestion of single doses of fresh-squeezed orange juice versus commercially processed orange juice in healthy humans. J. Agric. Food Chem. 2014, 62, 12576-12584. [CrossRef]

143. Actis-Goretta, L.; Dew, T.P.; Lévèques, A.; Pereira-Caro, G.; Rein, M.; Teml, A.; Schäfer, C.; Hofmann, U.; Schwab, M.; Eichelbaum, M.; et al. Gastrointestinal absorption and metabolism of hesperetin-7-O-rutinoside and hesperetin-7-O-glucoside in healthy humans. Mol. Nutr. Food Res. 2015, 59, 1651-1662. [CrossRef]

144. Borges, G.; Lean, M.E.J.; Roberts, S.A.; Crozier, A. Bioavailability of dietary (poly)phenols: A study with ileostomists to discriminate between absorption in small and large intestine. Food Funct. 2013, 4, 754-762. [CrossRef] [PubMed]

145. Lévèques, A.; Actis-Goretta, L.; Rein, M.J.; Williamson, G.; Dionisi, F.; Giuffrida, F. UPLC-MS/MS quantification of total hesperetin and hesperetin enantiomers in biological matrices. J. Pharm. Biomed. Anal. 2012, 57, 1-6. [CrossRef] [PubMed]

146. Donovan, J.L.; Crespy, V.; Oliveira, M.; Cooper, K.A.; Gibson, B.B.; Williamson, G. (1)-Catechin is more bioavailable than (2)-catechin: Relevance to the bioavailability of catechin from cocoa. Free Radic. Res. 2006, 40, 1029-1034. [CrossRef] [PubMed]

147. Teng, X.W.; Roupe, K.A.; Davies, N.M.; Jaime, A.Y. Stereospecific high-performance liquid chromatographic analysis of hesperetin in biological matrices. J. Pharm. Biomed. Anal. 2005, 37, 591-595.

148. Yáñez, J.A.; Remsberg, C.M.; Miranda, N.D.; Vega-Villa, K.R.; Andrews, P.K.; Davies, N.M. Pharmacokinetics of selected chiral flavonoids: Hesperitin, naringenin and eriodictyol in rats and their content in fruit juices. Biopharm. Drug Dispos. 2008, 29, 63-82. [CrossRef]

149. Brand, W.; Shao, J.; Hoek-Van Den Hil, E.F.; Van Elk, K.N.; Spenkelink, B.; De Haan, L.H.J.; Rein, M.J.; Dionisi, F.; Williamson, G.; Van Bladeren, P.J.; et al. Stereoselective conjugation, transport and bioactivity of S- and R-hesperetin enantiomers in vitro. J. Agric. Food Chem. 2010, 58, 6119-6125. [CrossRef]

150. Majumdar, S.; Srirangam, R. Solubility, stability, physicochemical characteristics and in vitro ocular tissue permeability of hesperidin: A natural bioflavonoid. Pharm. Res. 2009, 26, 1217-1225. [CrossRef]

151. Aschoff, J.K.; Kaufmann, S.; Kalkan, O.; Neidhart, S.; Carle, R.; Schweiggert, R.M. In vitro bioaccessibility of carotenoids, flavonoids, and vitamin $\mathrm{C}$ from differently processed oranges and orange juices (Citrus sinensis (L.) osbeck). J. Agric. Food Chem. 2015, 63, 578-587. [CrossRef] 
152. Gil-Izquierdo, A.; Gil, M.I.; Tomás-Barberán, F.A.; Ferreres, F. Influence of industrial processing on orange juice flavanone solubility and transformation to chalcones under gastrointestinal conditions. J. Agric. Food Chem. 2003, 51, 3024-3028. [CrossRef]

153. Bai, J.; Manthey, J.A.; Ford, B.L.; Luzio, G.; Cameron, R.G.; Narciso, J.; Baldwin, E.A. Effect of extraction, pasteurization and cold storage on flavonoids and other secondary metabolites in fresh orange juice. J. Sci. Food Agric. 2013, 93, 2771-2781. [CrossRef]

154. Gil-Izquierdo, A.; Gil, M.I.; Ferreres, F. Effect of processing techniques at industrial scale on orange juice antioxidant and beneficial health compounds. J. Agric. Food Chem. 2002, 50, 5107-5114. [CrossRef] [PubMed]

155. Santos, A.C.; Pereira, I.; Pereira-Silva, M.; Ferreira, L.; Caldas, M.; Collado-González, M.; Magalhães, M.; Figueiras, A.; Ribeiro, A.J.; Veiga, F. Nanotechnology-based formulations for resveratrol delivery: Effects on resveratrol in vivo bioavailability and bioactivity. Colloids Surf. B Biointerfaces 2019, 180, 127-140. [CrossRef] [PubMed]

156. Hu, B.; Liu, X.; Zhang, C.; Zeng, X. Food macromolecule based nanodelivery systems for enhancing the bioavailability of polyphenols. J. Food Drug Anal. 2017, 25, 3-15. [CrossRef] [PubMed]

157. Gasa-Falcon, A.; Odriozola-Serrano, I.; Oms-Oliu, G.; Martín-Belloso, O. Nanostructured Lipid-Based Delivery Systems as a Strategy to Increase Functionality of Bioactive Compounds. Foods 2020, 9, 325. [CrossRef]

158. Li, T.; Teng, D.; Mao, R.; Hao, Y.; Wang, X.; Wang, J. Recent progress in preparation and agricultural application of microcapsules. J. Biomed. Mater. Res. A 2019, 107, 2371-2385. [CrossRef]

159. Ordovas, J.M.; Ferguson, L.R.; Tai, E.S.; Mathers, J.C. Personalised nutrition and health. BMJ 2018, $361,1-7$. [CrossRef]

160. Palmnäs, M.; Brunius, C.; Shi, L.; Rostgaard-Hansen, A.; Torres, N.E.; González-Domínguez, R.; Zamora-Ros, R.; Ye, Y.L.; Halkjær, J.; Tjønneland, A.; et al. Perspective: Metabotyping-A Potential Personalized Nutrition Strategy for Precision Prevention of Cardiometabolic Disease. Adv. Nutr. 2019, 1-9. [CrossRef]

161. González-Peña, D.; Brennan, L. Recent Advances in the Application of Metabolomics for Nutrition and Health. Annu. Rev. Food Sci. Technol. 2019, 10, 479-519. [CrossRef]

162. Selma, M.V.; Romo-Vaquero, M.; García-Villalba, R.; González-Sarrías, A.; Tomás-Barberán, F.A.; Espín, J.C. The human gut microbial ecology associated with overweight and obesity determines ellagic acid metabolism. Food Funct. 2016, 7, 1769-1774. [CrossRef]

163. Tomás-Barberán, F.A.; García-Villalba, R.; González-Sarrías, A.; Selma, M.V.; Espín, J.C. Ellagic acid metabolism by human gut microbiota: Consistent observation of three urolithin phenotypes in intervention trials, independent of food source, age, and health status. J. Agric. Food Chem. 2014, 62, 6535-6538. [CrossRef] 